\title{
A Laboratory Investigation of the Probable Mechanisms of the Action of an Artificial Thunderstorm Cell on Model Aircraft Radomes
}

\author{
Nikolay Lysov ${ }^{1, *(\mathbb{D}}$, Alexander Temnikov ${ }^{1}$, Leonid Chernensky ${ }^{1}$, Alexander Orlov ${ }^{1}$, Olga Belova ${ }^{1}$, \\ Tatiana Kivshar ${ }^{1}$, Dmitry Kovalev ${ }^{1}$, Mikhail Belyakov ${ }^{2}$ iD and Vadim Voevodin ${ }^{1}$ \\ 1 Department of Electrophysics and High Voltage Technique, Moscow Power Engineering Institute, \\ National Research University, 111250 Moscow, Russia; TemnikovAG@mpei.ru (A.T.); \\ ChernenskyLL@mpei.ru (L.C.); OrlovAV@mpei.ru (A.O.); belovaos@mail.ru (O.B.); geratk@mail.ru (T.K.); \\ kovalevdi@mpei.ru (D.K.); voevodinvv@mpei.ru (V.V.) \\ 2 Department of Optoelectronic Systems, Smolensk Branch of Moscow Power Engineering Institute, \\ National Research University, 214013 Smolensk, Russia; bmw20100@mail.ru \\ * Correspondence: streamer.corona@gmail.com; Tel.: +7-9168456253
}

\section{check for} updates

Citation: Lysov, N.; Temnikov, A.; Chernensky, L.; Orlov, A.; Belova, O.; Kivshar, T.; Kovalev, D.; Belyakov, M.; Voevodin, V. A Laboratory Investigation of the Probable Mechanisms of the Action of an Artificial Thunderstorm Cell on Model Aircraft Radomes. Atmosphere 2021, 12, 1637. https://doi.org/ $10.3390 /$ atmos12121637

Academic Editor: Pavlo Kochkin

Received: 29 October 2021

Accepted: 3 December 2021

Published: 7 December 2021

Publisher's Note: MDPI stays neutral with regard to jurisdictional claims in published maps and institutional affiliations.

Copyright: (c) 2021 by the authors. Licensee MDPI, Basel, Switzerland. This article is an open access article distributed under the terms and conditions of the Creative Commons Attribution (CC BY) license (https:// creativecommons.org/licenses/by/ $4.0 /)$.

\begin{abstract}
The results of experimental laboratory investigations of possible mechanisms of the impact of lightning and thunderclouds on aircraft radomes and equipment inside them are presented. An artificial thunderstorm cell of negative polarity and model aircraft radomes with lightning diverter strips have been used. Experiments have shown that the discharge processes in a radome model significantly depend on the magnitude of the charge that accumulates on the inner and outer surfaces of the radome shell. It is established that the accumulation of large-magnitude charges of different signs on the outer and/or inner surface of the radome (up to hundreds of $\mu \mathrm{C} / \mathrm{m}^{2}$ ) shell leads to a multivariance of the mechanisms of development of discharge processes inside the radome model, along its surface, and in the space near it. Significant influence of the "reverse" discharge from the antenna model under the radome on the types of current impulses recorded on the antennas under impact of the artificial thunderstorm cell is established. Peculiarities of the discharge formation in the radome model when using solid and segmented diverter strips for its protection are revealed. Parameters of the current impulses registered on the diverter strips and the antennas have been determined. Based on the conducted research, the possible mechanisms of the impact of thunderclouds and lightning discharges on radio-transparent aircraft radomes and the equipment inside them are considered.
\end{abstract}

Keywords: lightning; model aircraft radome; artificial thunderstorm cell; lightning diverter strip; solid diverter strips; segmented diverter strips; simulation; discharge; surface charge

\section{Introduction}

In recent decades, the tasks related to the thunderstorm and lightning protection of the dielectric aircraft radome (and radio navigational equipment located under it) has become relevant again in the field of lightning physics and protection. Damage to the radome itself or its radio navigation equipment significantly decrease flight safety and may lead to aircraft crash [1-7].

The direct and indirect effect the lightning can have on an aircraft radome and its equipment may vary significantly. It is related to specific mechanism of action the lightning can have on the aircraft and its radomes $[1,2,7,8]$. Two main processes of lightning defeat can be discerned: lightning strokes between clouds or between clouds and ground intercepted by the airplane, and the strokes initiated by the airplane itself $[1-3,9]$. In the first case, discharge is formed very quickly. Most often the damage is sustained by the aircraft radome, which is affected by the maximum impulse of the lightning stroke current. In the second case, positive and negative leaders can be formed relatively slowly from the 
aircraft itself. These leaders can be either non-completed (and reach up to tens of meters in length) or result in the formation of a main stage current. The radome itself in this case is not affected by maximum current, since the leader formed on the aircraft nose drifts along the fuselage in the tail direction. Tens of milliseconds may pass since the moment of leader formation to the beginning of strong current phase of the main discharge stage (maximal backfire currents may reach up to 10-40 kA). Aircraft radome and equipment under it are mainly affected by the leaders whose maximal current values usually do not surpass hundreds of amperes.

Radio-transparent aircraft radomes are routinely equipped with lightning protection and undergo high voltage testing [3,7-10]. The main purpose of lightning protection equipment placed on a radome is to prevent the shell breakage and avoid damage to the antenna system inside it. Apart from this, it is necessary to consider that radio navigational equipment located under the radome and key autopilot systems connected to it may experience loss of function or even complete failure, which rapidly increases probability of an accident or a crash $[1,2,11-16]$.

The choice of radome lightning protection's structure is determined by a need to compromise between maximal protection efficacy and its minimal interference with electromagnetic waves. Existing constructions cannot eliminate risk of damage to the aircraft radome and/or failure of radio navigational equipment located under it as a result of atmospheric electricity. Therefore, in recent years investigations are being conducted to further perfect the lightning protection (including using various lightning diverter types) for aircraft radomes and equipment under them [4-9,15,17-23].

Existing methods of investigations and testing of aircraft radomes for lightning protection's efficacy are based on using impulse voltage generators and, less often, constant voltage sources $[8,9,14,18,24-30]$. High voltage or grounded electrodes during such investigations (including "reverse scheme" experiments) are usually presented by a rod with a spherical top, which is used to model a leader from a thundercloud approaching the aircraft, or a flat surface, which models thundercloud's electromagnetic field affecting the aircraft. Radar antenna under the radome covered on the surface by solid or segmented lightning strip diverters is modeled either by a sphere or a flat electrode with various orientation towards high voltage electrode [31]. A relatively slowly increasing high voltage switching impulse form D (50-250/200 $\mu$ s) is used to determine interception efficacy of lightning protection. Such impulse most closely reflects the characteristics of electric field's change in aircraft location area during the initial lightning attachment phase [30,32].

Possible mechanisms of lightning's effect on aircraft radome depending on the variants of its lightning protection structure were investigated in ONERA $[25,26]$ under "reverse scheme" using negative D form impulse. It was noted that for the case of radome's shell breakdown important role may have been played by forming of a bipolar leader from the top of radome model and discharge phenomena on the antenna located under the radome. Results of further investigation of lightning's effect on aircraft radome and suggestions for perfection of its testing methods were summarized in $[9,18,33]$.

The investigations $[4,5,17]$ conducted using impulse voltage generators, solid and segmented strip lightning diverters, and theoretical modeling have suggested that there is a preference to the use of segmented lightning diverter strips, since they allow for a better radio transparency of the radome and a lower effect of lightning on radome during air discharge formation between the segments.

Results of recent wide investigations of mechanisms of lightning effect on aircraft radome and efficacy of its lightning protection, which used impulse voltage generators, are presented in $[6-8,31]$. These publications review the efficacy of solid, segmented, and combined lightning protection strips as measured by the following parameters: the absence of breakdown, the place of initial leader attachment, and their durability to the lightning current stream.

However, the reproduction of electrophysical processes and mechanisms of action occurring between thunderclouds, lightning discharges, and aircraft radomes and their 
equipment, modeled during experiments using impulse voltage generators, may be incomplete. More specifically, electrode-only systems do not allow for fully modeling a situation of an aircraft approaching electrically active clouds, being in their vicinity, and interacting with them. In this case, apart from the impact of a slowly changing thundercloud's electrical field on radome and antenna under it, it is possible that not only the aircraft may be charged [34], but also the dielectric radome, which may create very specific conditions of this interaction.

Using artificial thunderstorm cloud (ATC) allows for physical modeling and investigating possible processes of interaction between aircraft radomes and their radio navigational equipment with thunderstorm cells and lightning discharges during the different stages of aircraft flight in thunderstorm conditions, and their physical mechanisms.

\section{Experimental Setup}

Experimental complex "Thunderstorm" has been created to investigate fundamental and practical problems of atmospheric electricity, lightning physics, and lightning protection of grounded and flying objects [35-39]. It allows the creation of artificial clouds of heavily charged aerosol with ultimate density of volume discharge (ATC), corresponding to electrically active thunderclouds, and makes it possible to induce various types of electric discharges characteristic to thunderclouds, from weak diffuse discharges to high-current return stroke stage (Figure 1). Experimental scheme during investigations of the mechanisms of effect from lightning and thunderclouds on radio-transparent aircraft radomes using ATC is shown in Figure 2.

A condensational generator of charged water aerosol has been used to create ATC. It has formed a cloud (several $\mathrm{m} 3$ in volume) of finely dispersed charged water drops, located at the $1 \mathrm{~m}$ above ground. Maximal potential of negatively charged ATC reached up to $1.3 \mathrm{MB}$. Maximal intensity of outer electrical field reached up to $10 \mathrm{kV} / \mathrm{cm}$ in the model radome's location (close to the grounded field), and up to $18 \mathrm{kV} / \mathrm{cm}$ at the border of charged aerosol cloud $[36,38,40]$.

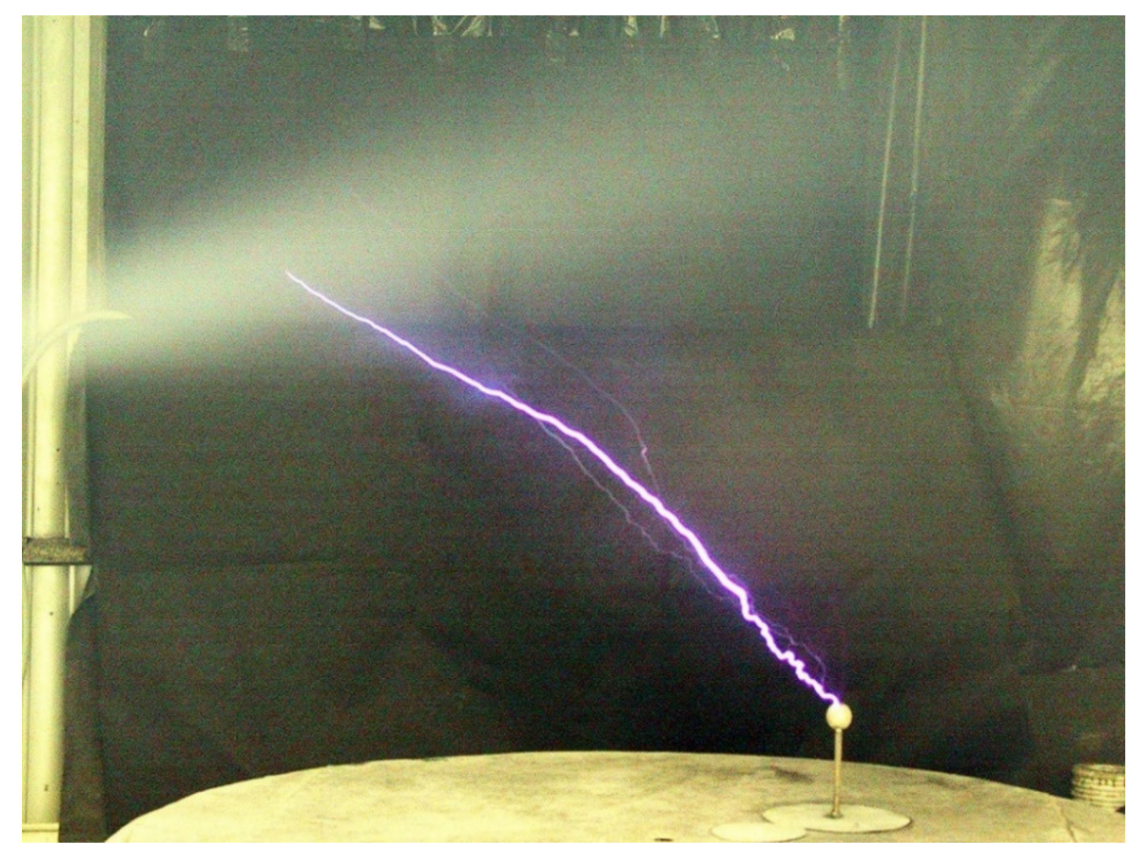

Figure 1. Characteristic picture of the discharge formation between artificial thunderstorm cell of negative polarity and the ground. 


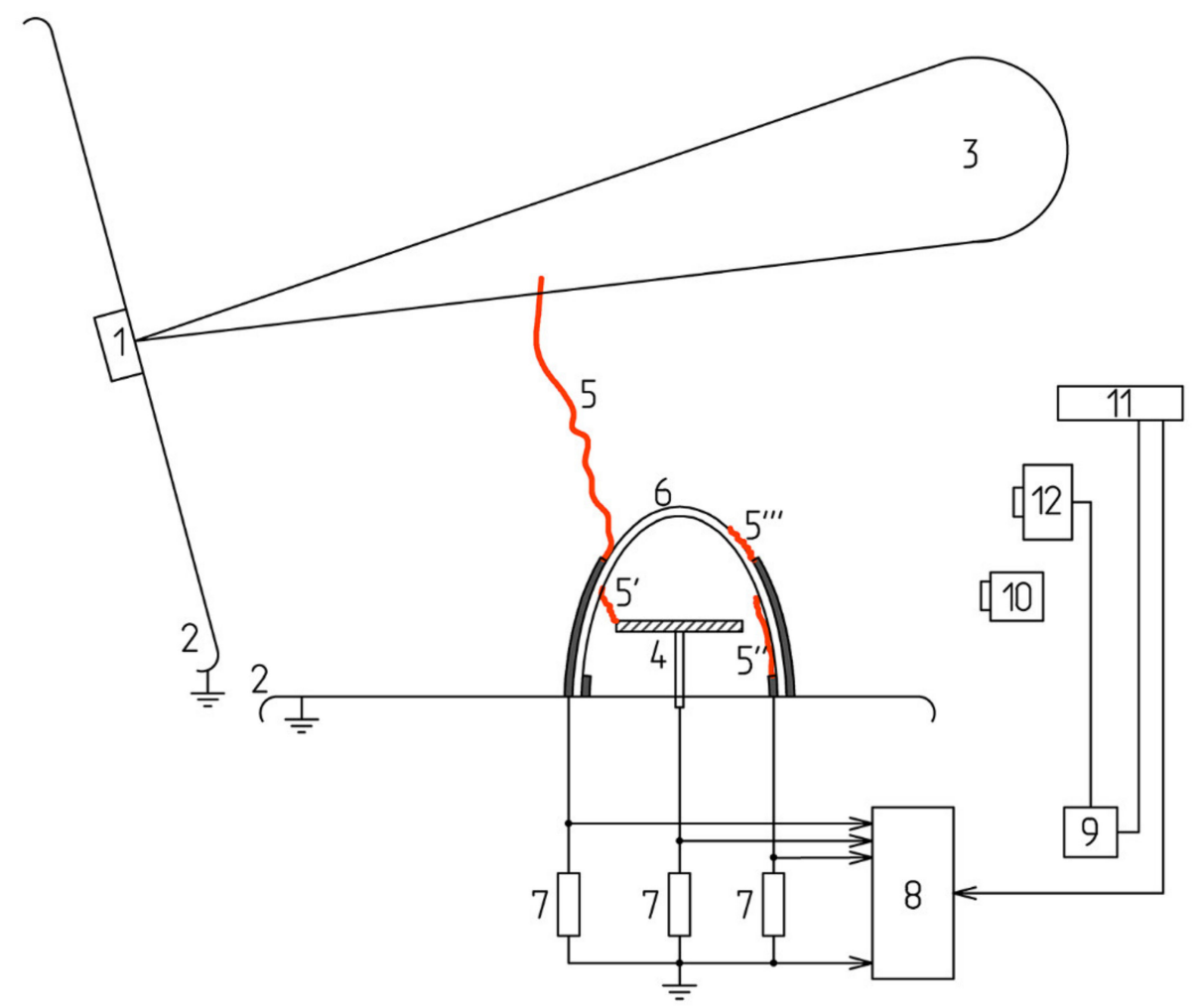

Figure 2. Scheme of experimental and measurement setup: 1-charged aerosol generator, 2grounded electrostatic screens, 3-artificial thunderstorm cell, 4-model antenna, 5-discharge from ATC, 5' - discharge phenomena between antenna and radome, 5", 5"' — surface discharges, 6 radome model, 7-shunts, 8-digital oscilloscope, 9-trigger generator, 10-digital camera Panasonic DMC-50, 11-photomultiplier tube, 12-electro-optical camera.

The artificial cloud of charged water aerosol has formed an outer electrical field, which caused sedimentation and accumulation of discharge on outer surface of the model dielectric radomes. This simulated the process of static electrification of the outer surface of the actual plane's radome due to various hydrometeors interacting with it at high speeds. Thin-walled, hollow, cylindrical dielectric elements (with half-ellipsoid tops) made from polyethylene terephtalate were used as models for hollow radio-transparent radomes. Thickness of dielectric shell of radome model was in diapason from $1.0 \mathrm{~mm}$ to $2.0 \mathrm{~mm}$, and its internal volume was from $3500 \mathrm{~cm}^{3}$ to $7000 \mathrm{~cm}^{3}$. Flat round antennas (square surface $100-150 \mathrm{~m}^{2}$ ) were also modeled during the experiments. The space between the edge of a model antenna and inner surface of radome's shell ranged from a few $\mathrm{mm}$ to a few $\mathrm{cm}$.

Different configurations of model lightning diverter strips used for protection of model radomes were used during these experiments to determine most possible variety of physical mechanisms involved. The following setups were modeled:

- Variant 1, Figure 3a: radomes without installed lightning protection;

- Variant 2, Figure 3b: radomes with vertical lightning diverter strips;

- Variant 3, Figure 3c: radomes with vertical segmented lightning diverter strips on outer surface. 

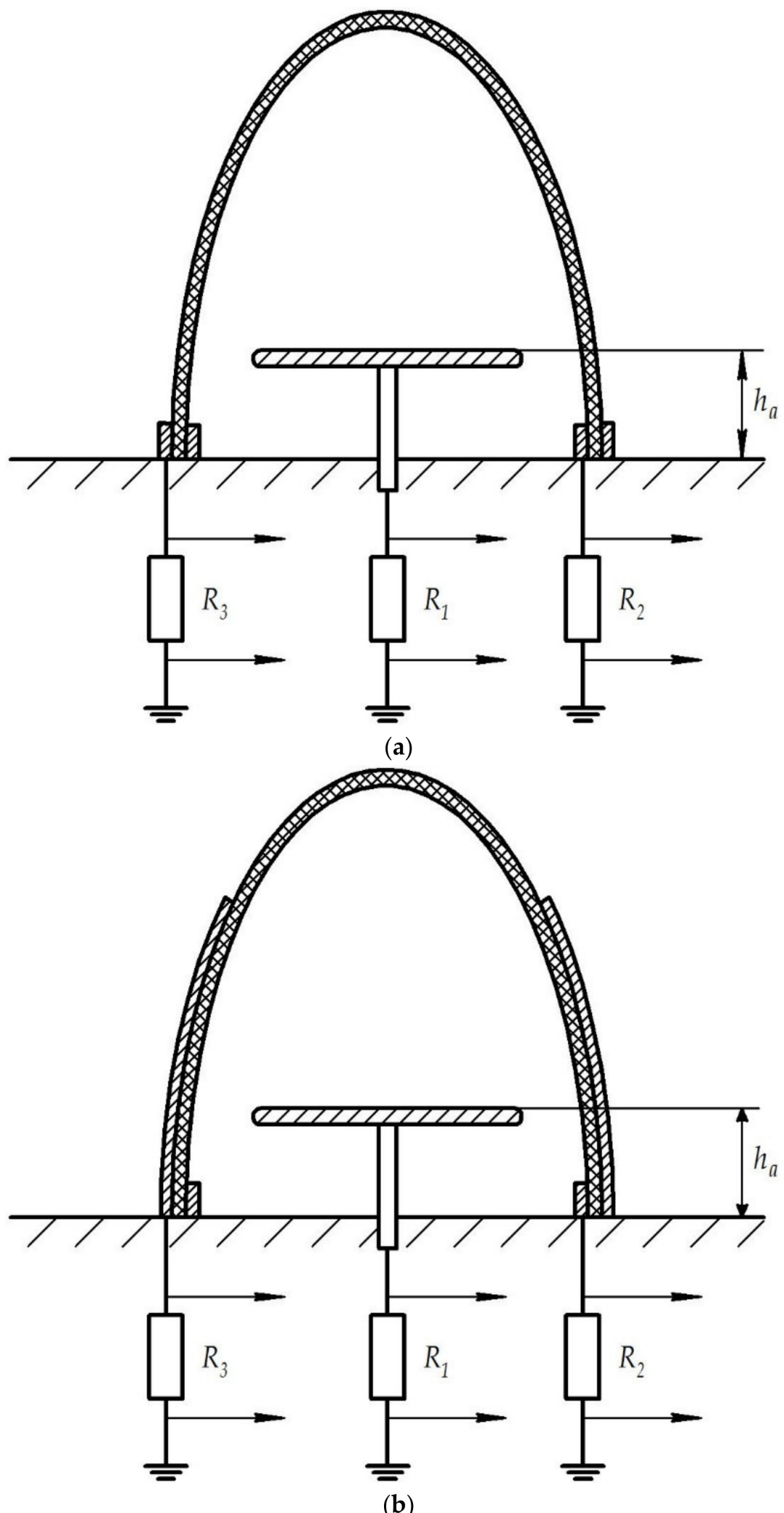

Figure 3. Cont. 


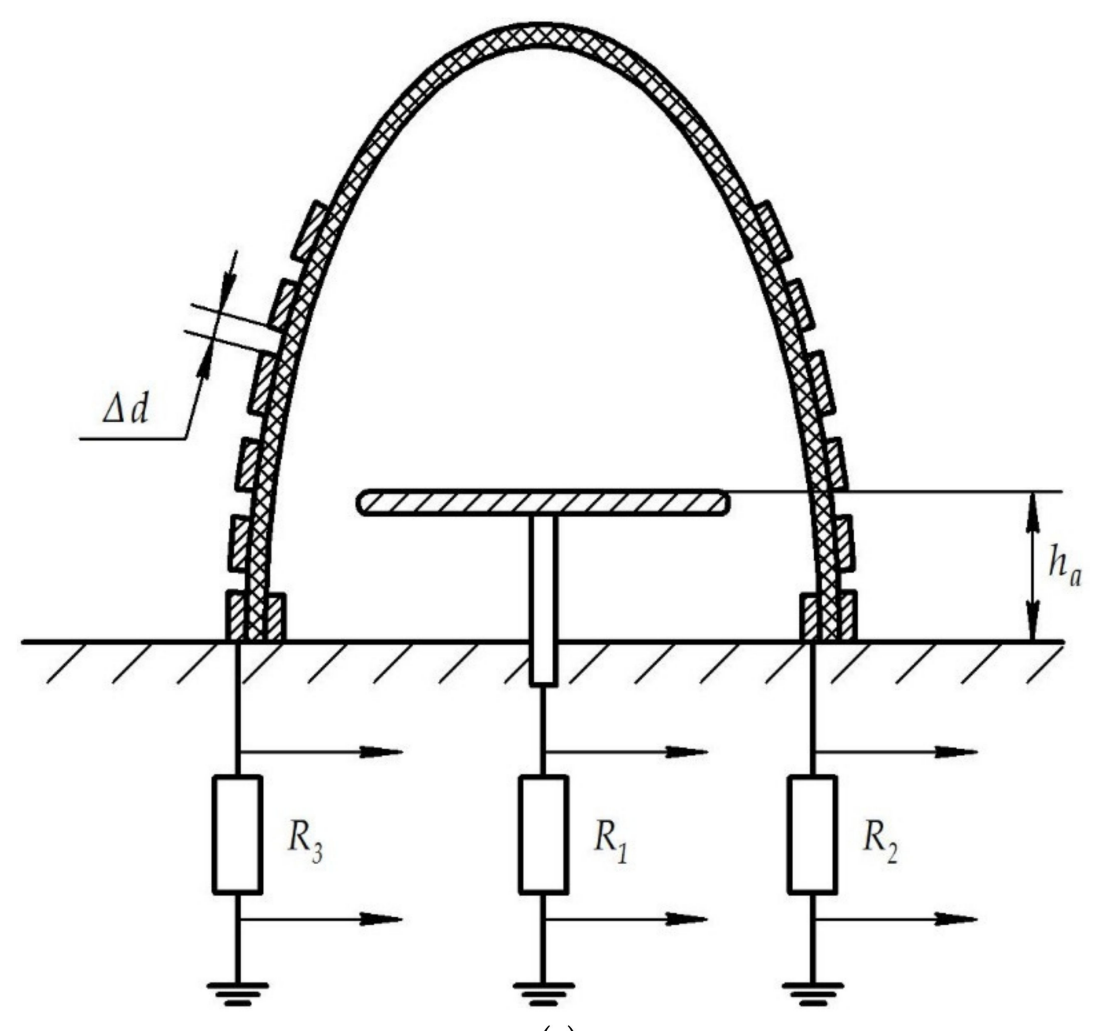

(c)

Figure 3. Various setups of lightning protection for aircraft radome ((a) radomes without installed lightning protection; (b) radomes with vertical lightning diverter strips; (c) radomes with vertical segmented lightning diverter strips on outer surface).

Solid circle diverter strips located on outer and inner surfaces in the radome's foundation have modeled radome's junction with the aircraft body's metallic elements. A total of 4 model solid or segmented lightning diverter strips were located on radome's outer surface. Strip width was $12 \mathrm{~mm}$. For model segmented diverter strips, the distance $\Delta d$ between the segments was a few $\mathrm{mm}$. The segments were rectangular. The length of solid or segmented electrodes have varied.

Digital memory oscillographs Tektronix DPO7254 or Tektronix TDS3054C (Tektronix, Inc., Beaverton, OR, USA) were used to register discharges' electrical characteristics. Signal was supplied onto oscillographs by low-inductance shunts of $0.5 \mathrm{Ohm}$. Parameters of the following processes were registered:

- $\quad$ signals (or discharge current, if present) induced on model antennas under the radome; - discharge current from electrodes on the outer surface of model radome;

- discharge current from stripe horizontal electrode on the inner surface of model radome.

Optic registration of the formation of discharge phenomena within radome model (on both inner and outer surface and in the air space between ATC and radome model) was done with a digital camera Panasonic Lumix DMC-FZ50 in bulb regimen during $15 \mathrm{~s}$.

At least 30 experiments were done for every configuration of model radome's lightning protection setup at least than 30 experiments.

\section{Analysis of Results and Discussion}

Experiments using ATC and model radomes with various lightning protection systems have detected the following physical mechanisms of the effect that electrically active (thunderstorm) clouds and their discharges may have on hollow radio-transparent aircraft radomes and antennas located underneath. It has been determined that phenomenology of spark discharge development in the space "ATC—model of radome with antenna inside" 
significantly depends on the value of discharge accumulated on inner and outer surfaces of radome's shell. It has been discovered that one of the key mechanisms of the effect of ATC on radome is accumulation of critical charges (tens and hundreds of $\mu \mathrm{C} / \mathrm{m}^{2}$ ) of different polarity on the radome's surface, which increases probability of its shell's puncture (Figure 4), or allows powerful discharges to form from antenna under the radome and further along radome's surface (Figure 5). It is specifically this accumulation of powerful different polarity charges on the inner/outer surfaces of radome's shell that leads to the multiple variants of discharge phenomena development inside, on the surface, and around the model radome.

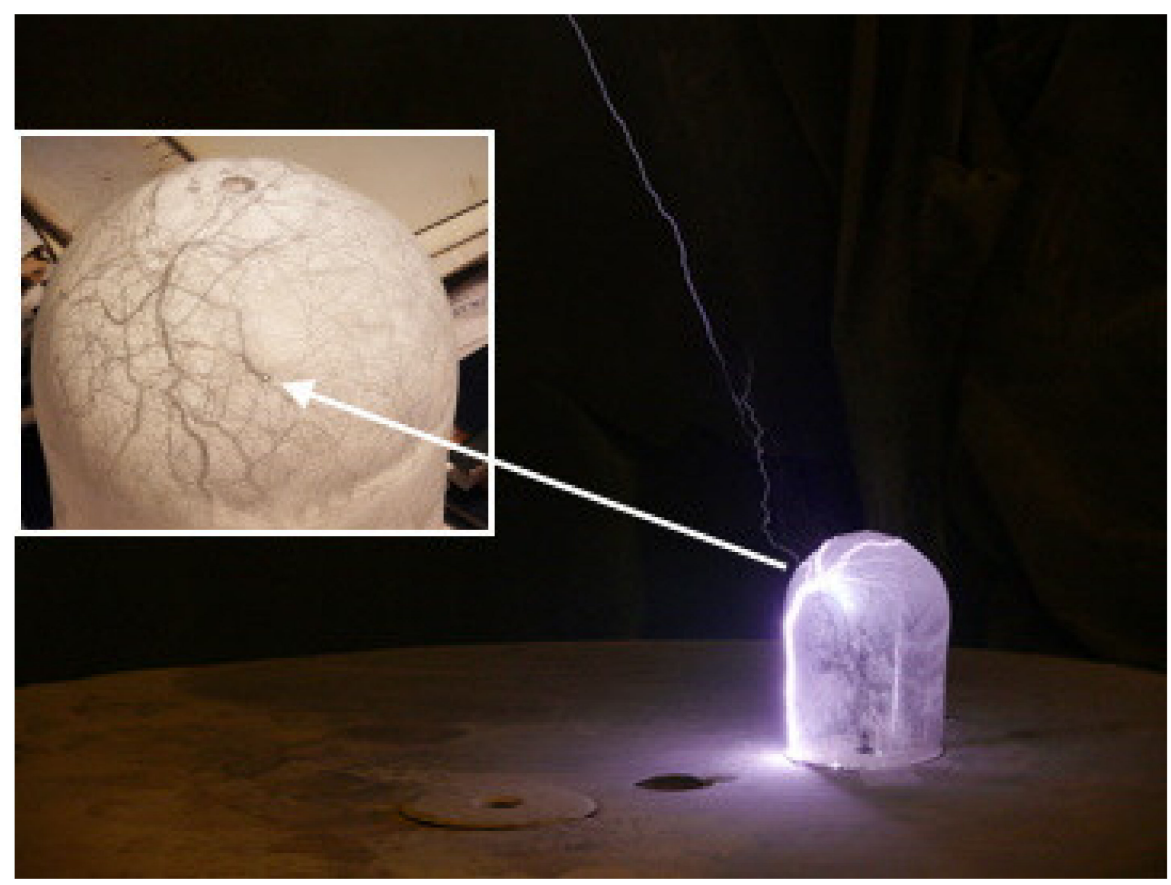

Figure 4. Puncture of radome's shell due to accumulation of charges on the outer and inner surfaces of the radome.

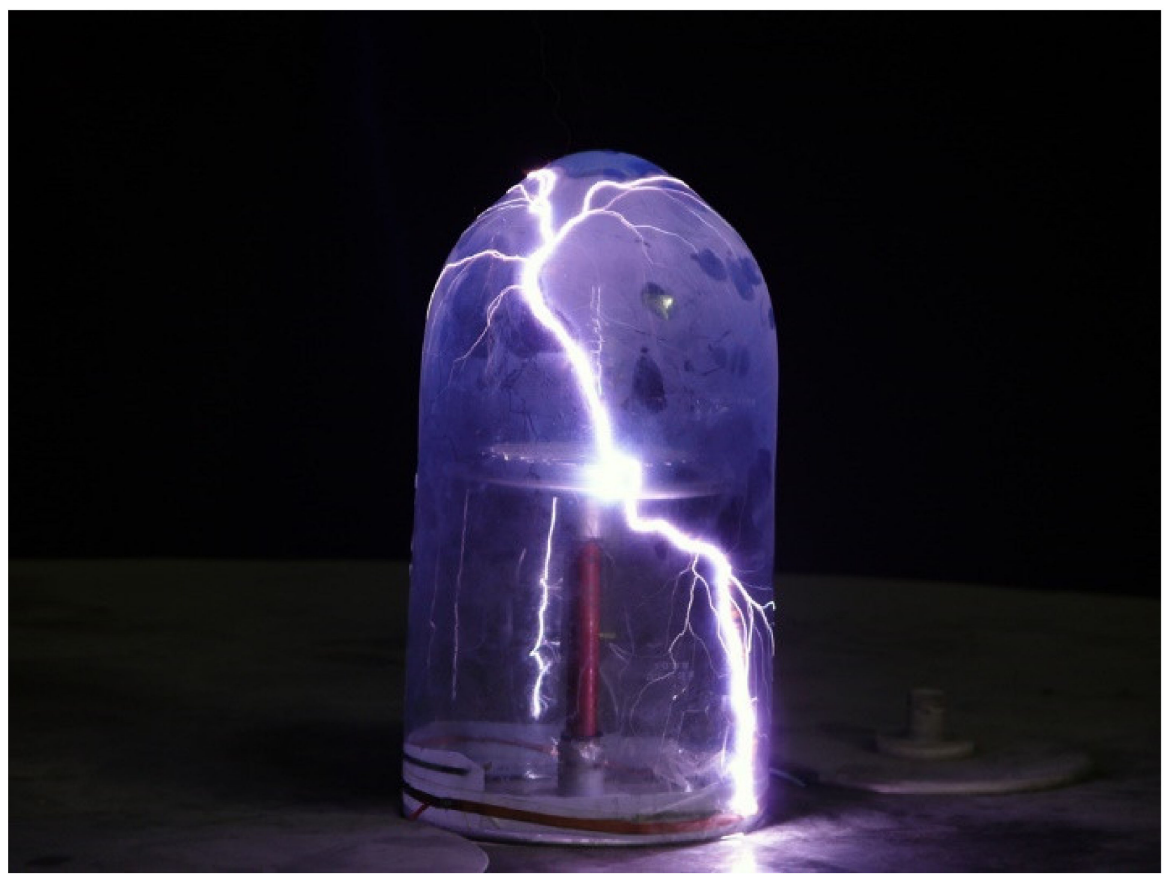

Figure 5. Discharge formation in model radome without lightning protection. 
Experiments with model radomes without lightning diverter strips on their surface have shown that in most of the cases the formation of discharge phenomena along the surfaces of model radome starts even before any expressed discharges in the space between ATC and model radome are formed (Figure 5). It was also noted that a model antenna located under the radome under ATC influence may form a powerful spark discharge of the same polarity as the ATC itself (so-called reverse discharge, Figure 6). Its amplitude could exceed $200 \mathrm{~A}$, which is several times higher than impulse current amplitude of main stage discharge between ATC and the ground without model radome [38], Figure 7.

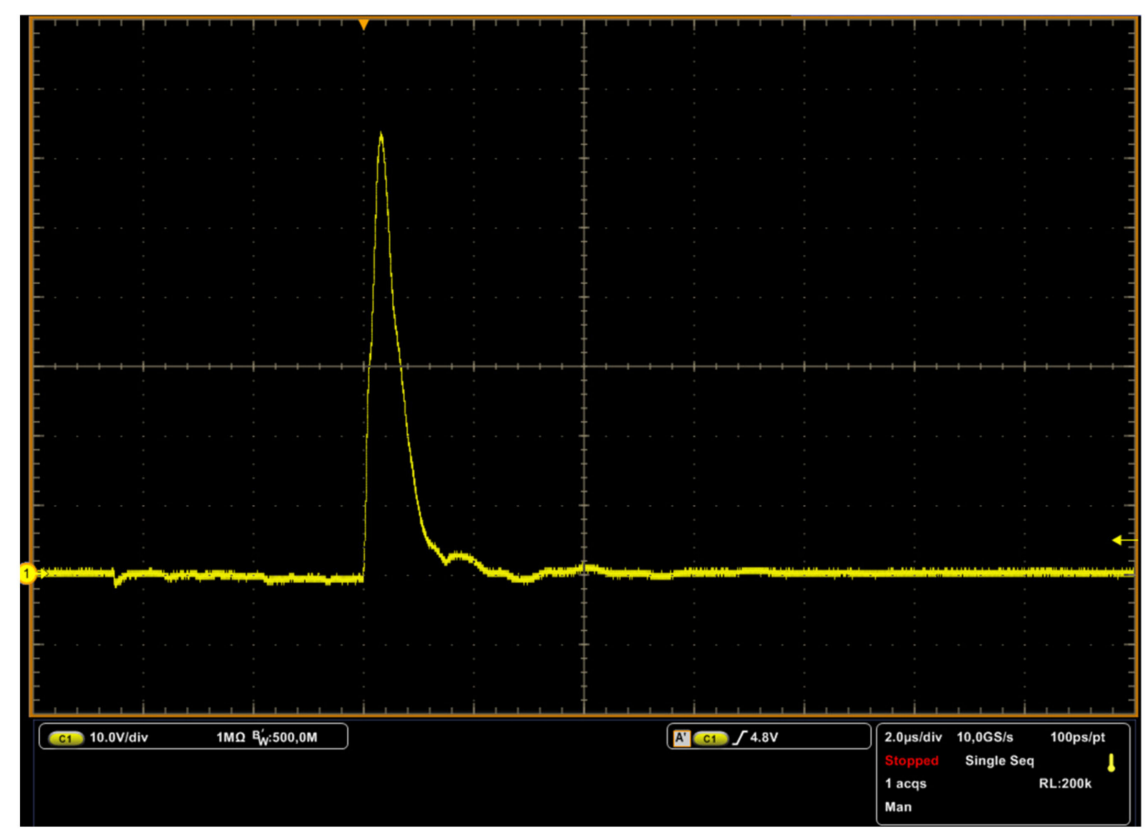

Figure 6. Characteristic oscillogram of reverse discharge current developing from the model antenna under radome (shunt $0.5 \mathrm{Ohm}$ ).

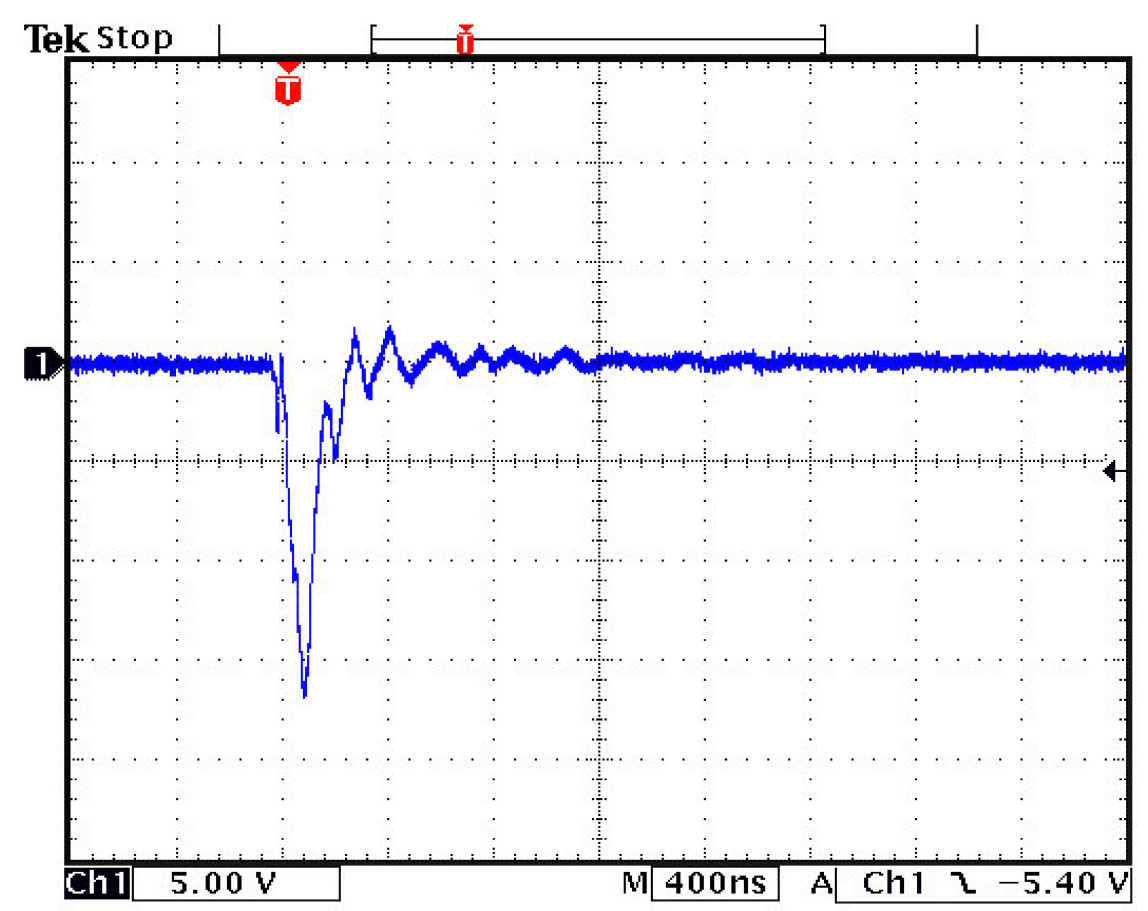

Figure 7. Characteristic oscillogram of discharge current between ATC and the ground (shunt 0.5 Ohm). T—trig moment, 1—channel number. 
This phenomenon can be explained as follows: a corona discharge of avalanche type is initiated and persists for some time on the antenna in the outer electrical field, created by ATC and accumulated charge on the outer radome surface due to the precipitation of aeroions and charged aerosol particles onto it. As a result, a charge (which is opposite in polarity to ATC's charge) is deposited and accumulated on the radome's inner surface.

With a sharp decrease of the outer field (which may occur e.g., when a part of the cloud charge is neutralized by various discharge processes, and/or when the discharge is located along the outer surface of the radome) this charge, deposited on the inner surface of the radome, can change the direction of the electric field's intensity vector at the antenna location to the opposite, and cause a "reverse" discharge from the electrode inside the radome. Moreover, the formation of a discharge along one surface of the radome (for example, the outer one) can also provoke an almost simultaneous development of the discharge along the other surface (the inner one).

The influence of the variant of the model radome's lightning protection system on the formation of characteristic discharges in the radome, their intensity and parameters of the current impulse (induced signal) on the antenna has been established. At the same time, it should be noted that as experimental studies have shown, the maximum signal intensity on the antenna for all options for radome's lightning protection and characteristic types of antenna devices under it is provided by "reverse" discharges of the same polarity as ATC that is affecting it. In the absence of lightning diverter strips on the radome's surface (Variant 1), the most powerful reverse discharges from the antenna model under the radome have formed. In general, the presence of lightning diverter strips on the radome's outer surface reduces the intensity of the discharge from the antenna under the radome, but does not exclude the formation of powerful discharges from the electrodes inside it and surface discharges on the outer and inner surfaces of the radome model (Figures 8-11).

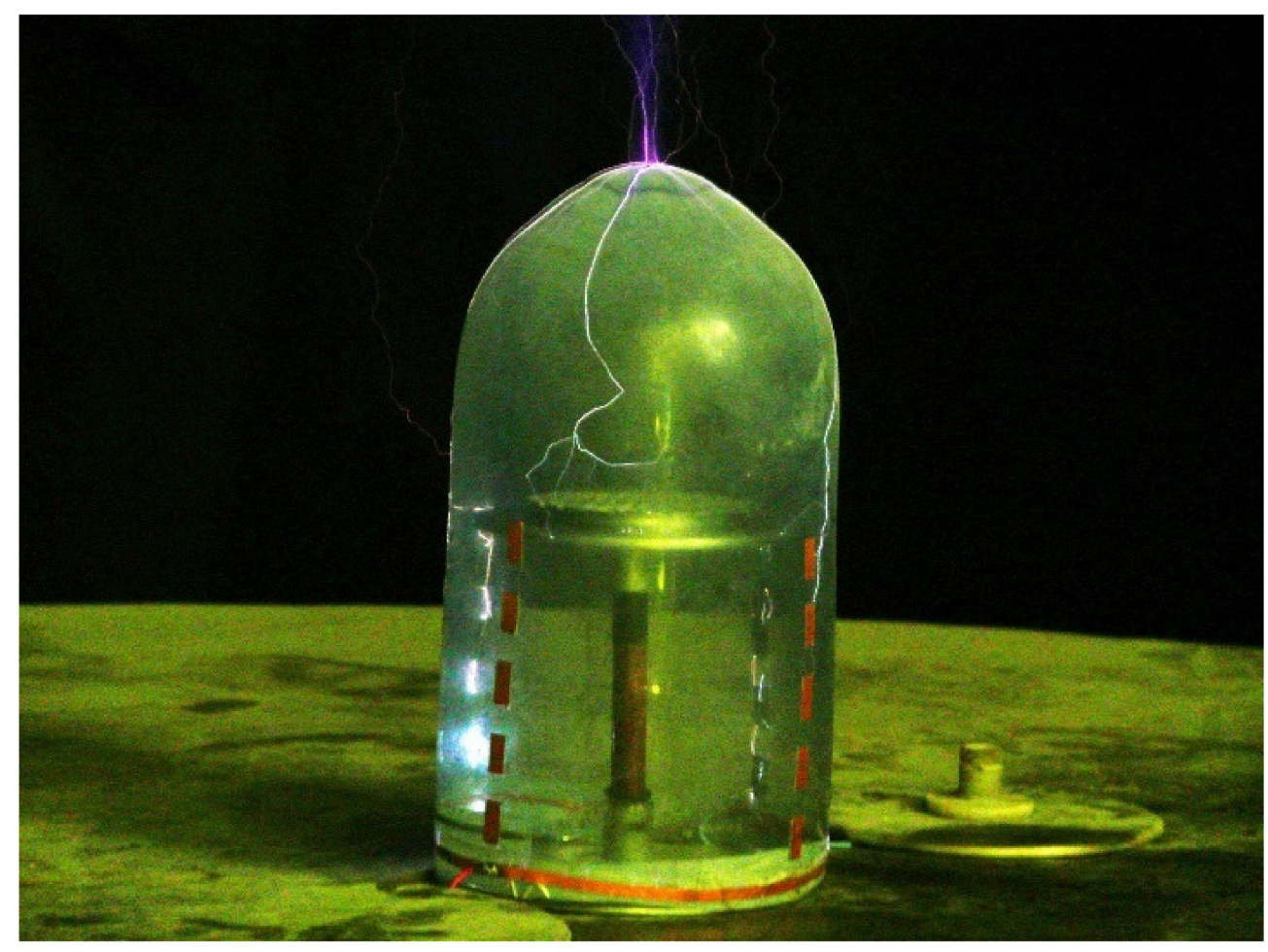

Figure 8. Discharge formation in radome model in the presence of segmented electrodes on its outer surface. 


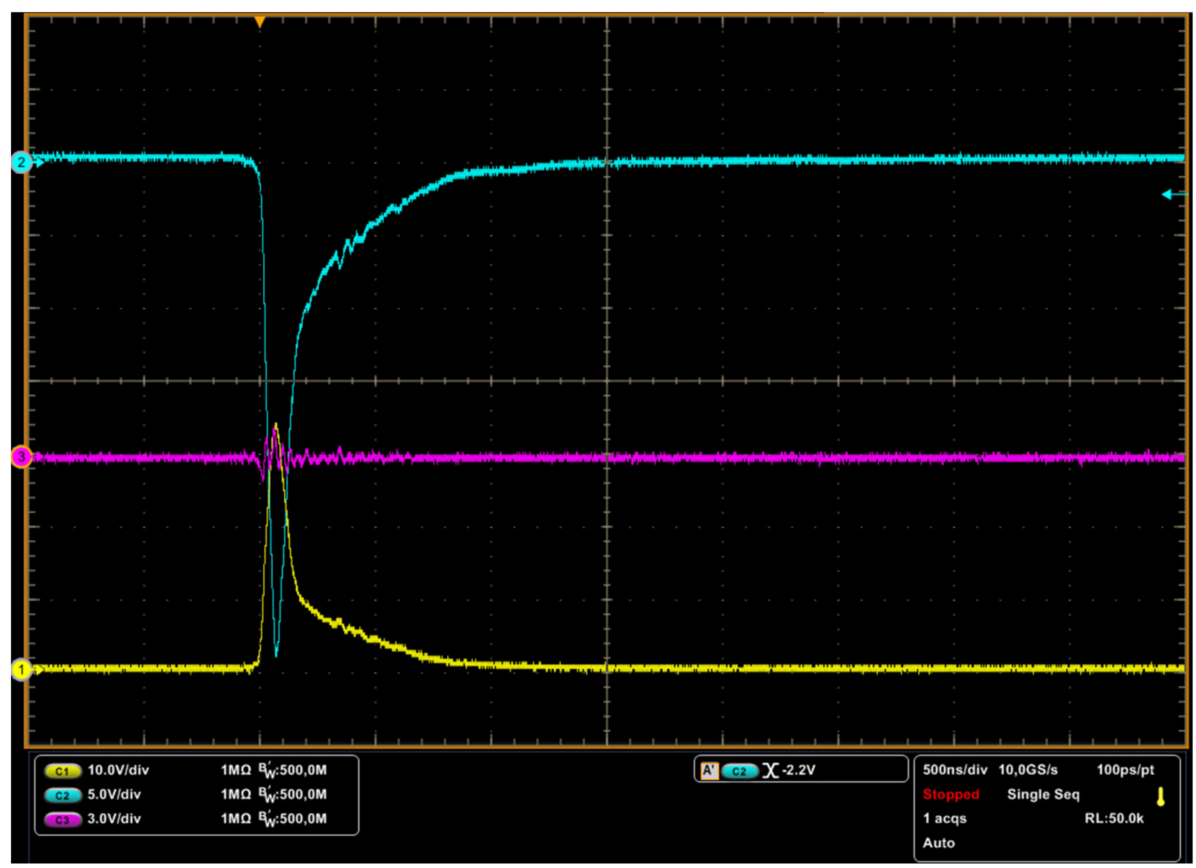

Figure 9. Oscillograms of reverse discharge current from the model antenna (yellow signal), discharge current from the segmented electrodes (cyan signal), and along the radome's inner surface (magenta signal) (shunts $0.5 \mathrm{Ohm}$ ).

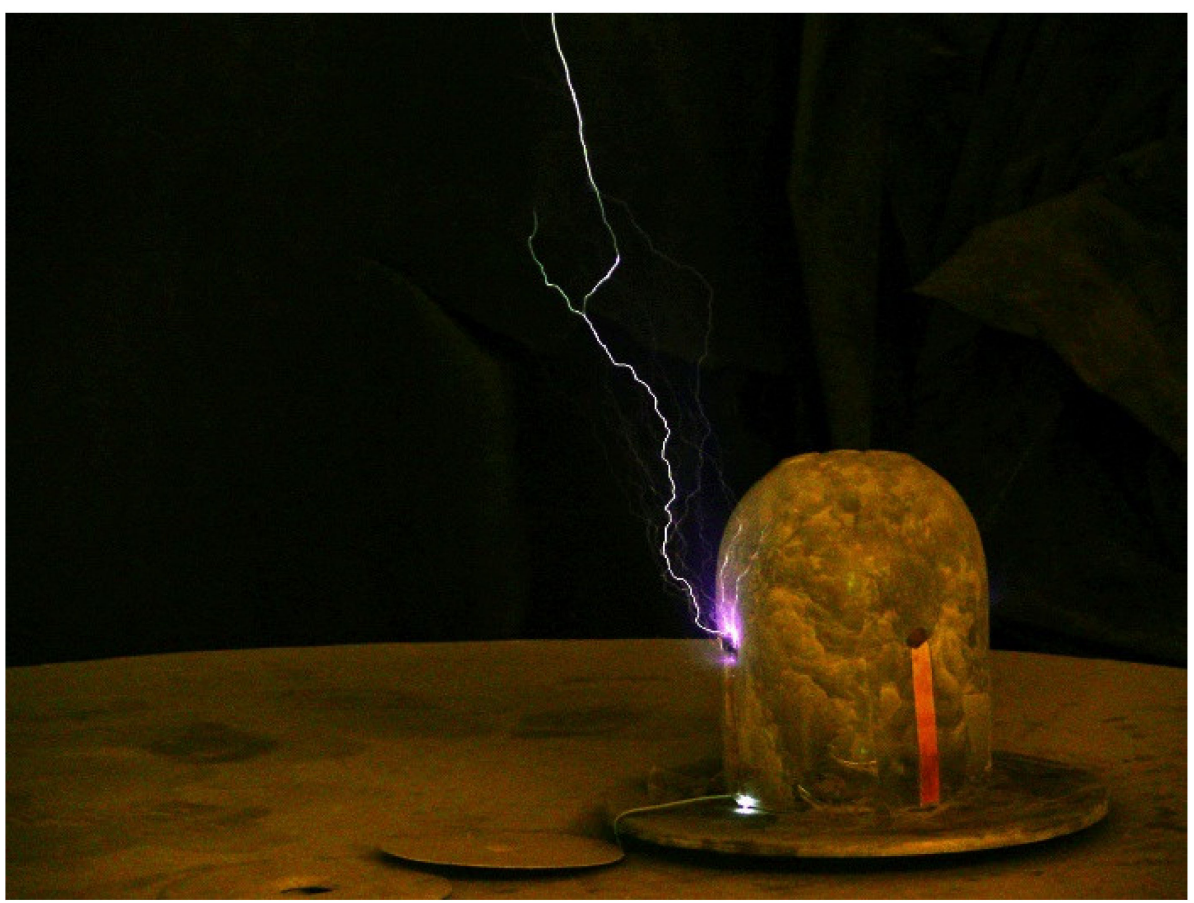

Figure 10. Discharge formation in radome model in the presence of solid stripe electrodes on its outer surface. 


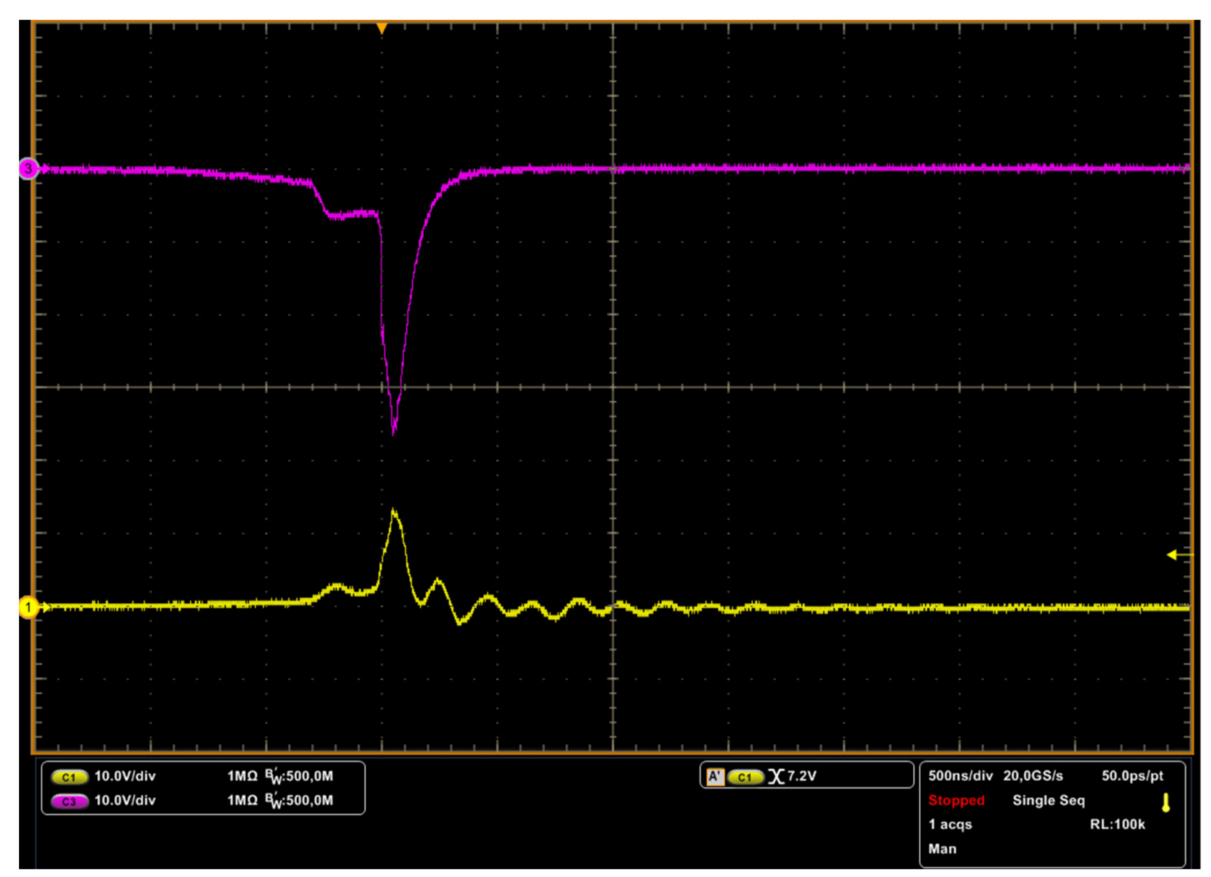

Figure 11. Oscillograms of reverse discharge current from the model antenna (yellow signal), discharge current from the solid stripe electrodes (magenta signal) (shunts $0.5 \mathrm{Ohm}$ ).

In general, the following types of discharges formed in the interval "ATC-radome model with models of antenna and lightning diverters" play a significant role in the formation of a current impulse (signal) on the antenna model under the radome:

- "reverse" discharge from the antenna model under the radome with a maximum amplitude of several hundred amperes, formed due to the charge accumulated on the inner surface of the radome shell and providing the most intense effect on the antenna model;

- discharge reaching amplitude values of several hundred amperes, occurring on the outer and/or inner surface of the radome shell, which ensures that the charge accumulated on the surface flows down to the ground (fuselage);

- a discharge between ATC and a lightning diverter on the radome's outer surface, which could be accompanied by the simultaneous formation of a discharge on the outer surface of the radome shell.

The following should be also noted: In the presence of a strip lightning diverter on the radome's outer surface the priority path of discharge formation is a combined discharge, which consists of a discharge developing between an electrically active cloud and a lightning diverter, and a discharge along the outer surface of the radio-transparent radome. In the presence of a segment lightning diverter on the radome's outer surface, an essential role in the formation of the combined discharge is played by the formation of a discharge along the outer surface of the radome with the participation of lightning diverter segments. The closer the antenna was to the walls of the radome, the more powerful in all parameters was the discharge to the antenna, since it is the discharge processes between the edge of the antenna and the charge deposited on the inner surface of the radome shell that play significant role in the formation of the current impulse on the antenna under the radome.

All this leads to a variety of forms of current impulses that can be formed on the antenna under the radome with different versions of its lightning protection (Table 1). The current impulses of the first (Figures 6 and 9) and second (Figure 11) types were determined, first, by reverse discharges between the edge of the antenna and the inner surface of the radome shell. Current impulses of the third type (Figure 12) were formed by a combination of currents of less powerful reverse discharges and displacement currents 
induced at the antenna by the surface discharges in the radome and discharges between lightning diverters on the outer surface and ATC. Current impulses of the fourth type (Figure 13) were formed in the absence of reverse discharges from the antenna due to displacement currents induced on the antenna by surface discharges in the radome and discharges between lightning diverters on the outer surface and an ATC.

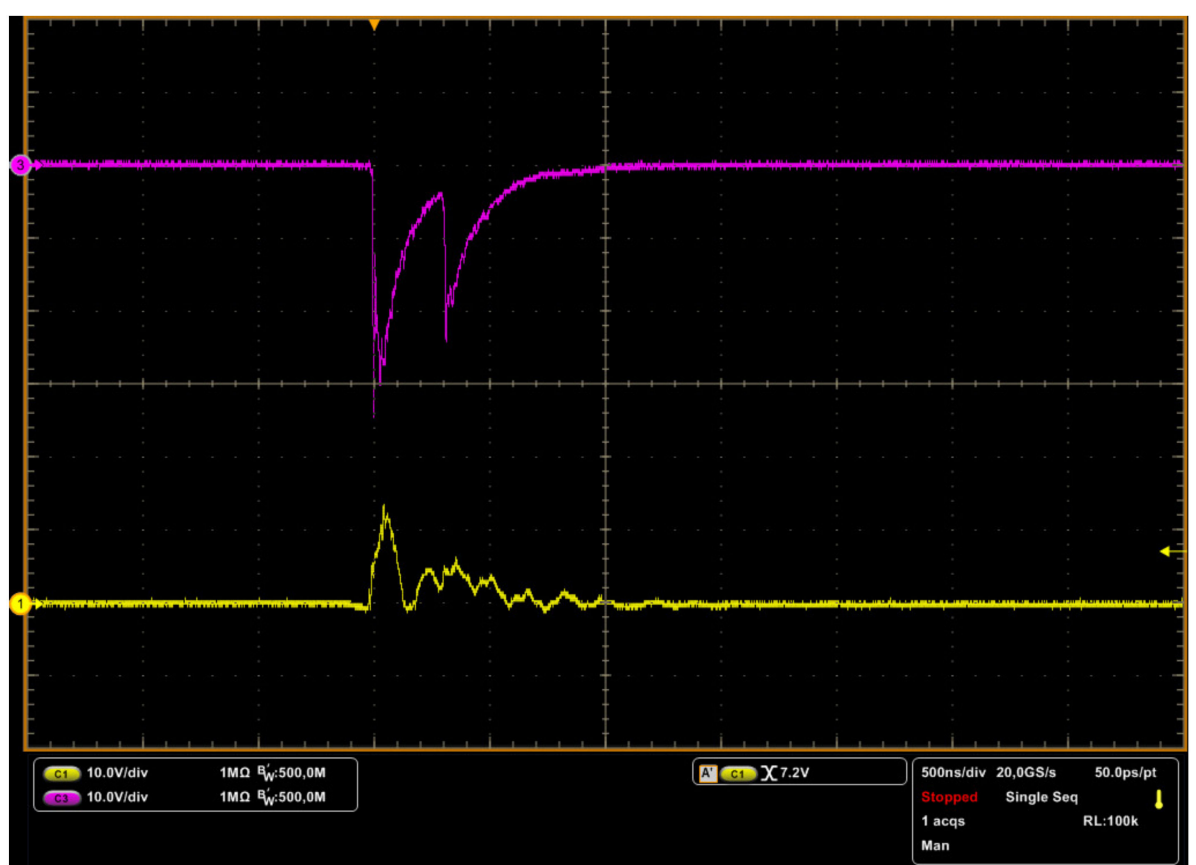

Figure 12. Oscillograms of current impulse of third type on the model antenna (yellow signal), discharge current from the solid stripe electrodes (magenta signal) (shunts $0.5 \mathrm{Ohm}$ ).

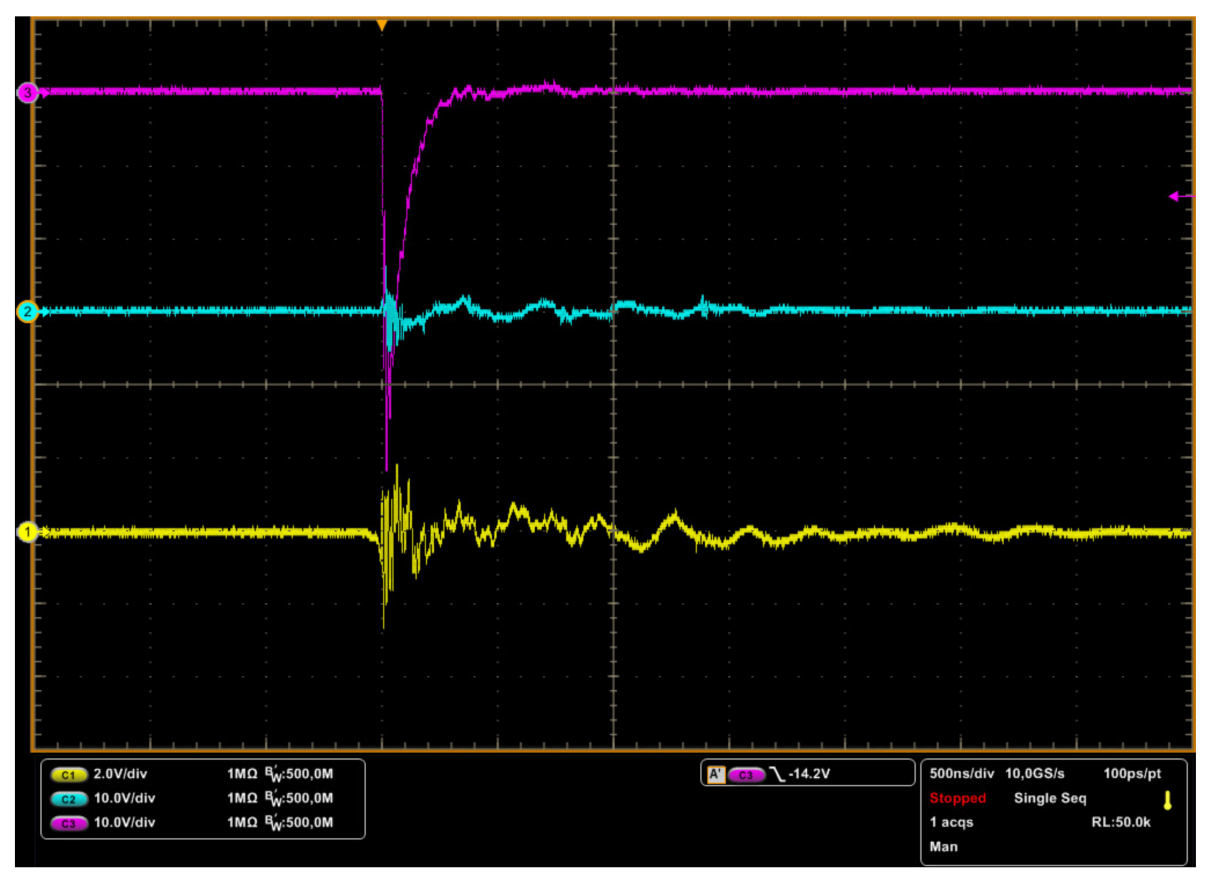

Figure 13. Oscillograms of current impulse of fourth type on the model antenna (yellow signal), discharge current from the segmented electrodes (magenta signal), and along the radome's inner surface (cyan signal) (shunts 0.5 Ohm). 
Table 1. Characteristic types of impulses recorded on the antennas under the radome model for various versions of its lightning protection.

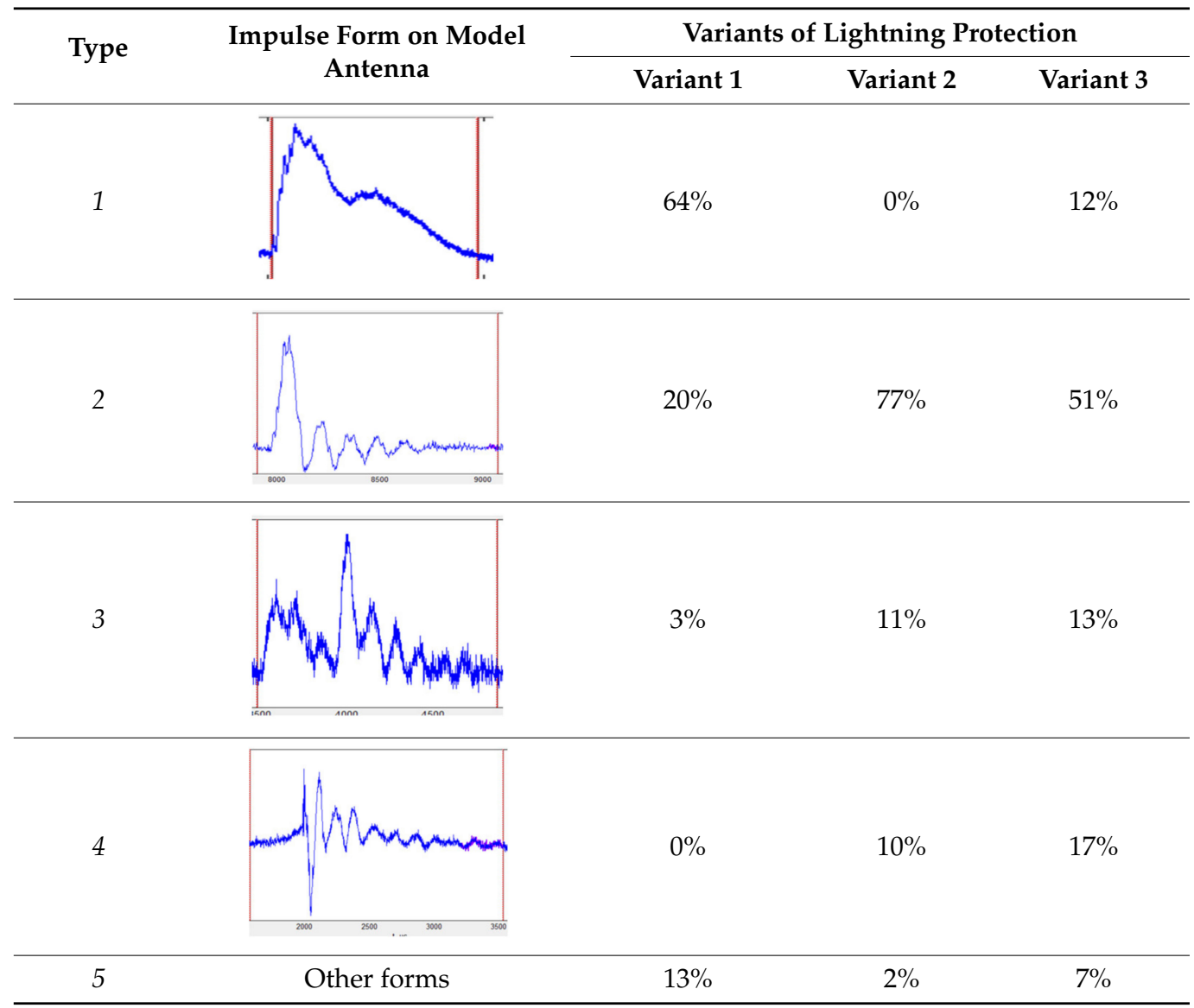

The variety of discharge processes that are formed between the models of solid or segmented strip lightning diverters and ATC and along the outer surface of the radome model, and, accordingly, the variety of forms of signals induced by them on model antennas, leads to a significant spread in the values of parameters of both the current impulses on models of lightning diverters and the signals recorded on the antennas (Tables 2 and 3).

Table 2. Parameters of current impulses recorded on the model of a lightning diverter on the radome's outer surface for different variants of its lightning protection (average value, range).

\begin{tabular}{ccc}
\hline Parameter & Variant 2 & Variant 3 \\
\hline \multirow{2}{*}{ Amplitude, A } & 39.1 & 19.4 \\
& $(2.7 \div 90.7)$ & $(1.9 \div 82.4)$ \\
\hline \multirow{2}{*}{ Steepness, A/ns } & 7.1 & 5.9 \\
& $(0.09 \div 36.4)$ & $(0.08 \div 27.4)$ \\
\hline \multirow{2}{*}{ Duration, ns } & 1230 & 1370 \\
& $(530 \div 5200)$ & $(360 \div 6290)$ \\
\hline \multirow{2}{*}{ Charge, $\mathrm{nC}$} & 6250 & 5760 \\
& $(830 \div 11,266)$ & $(230 \div 18,600)$ \\
\hline
\end{tabular}


Table 3. Parameters of signals recorded on the model of a flat antenna under the model of the fairing with different variants of its lightning protection (average value, range).

\begin{tabular}{cccc}
\hline Parameter & Variant 1 & Variant 2 & Variant 3 \\
\hline \multirow{2}{*}{ Amplitude, A } & 33.4 & 23.1 & 12.3 \\
& $(13.4 \div 162.3)$ & $(1.7 \div 82.7)$ & $(0.9 \div 121.7)$ \\
\hline \multirow{2}{*}{ Duration, $\mathrm{ns}$} & 2967 & 2158 & 1970 \\
& $(1415 \div 5638)$ & $(810 \div 7075)$ & $(430 \div 7128)$ \\
\hline \multirow{2}{*}{ Charge, $\mathrm{nC}$} & 24,874 & 6370 & 5980 \\
& $(4672 \div 94,397)$ & $(2835 \div 16,400)$ & $(1107 \div 31,080)$ \\
\hline
\end{tabular}

The largest values of the amplitude of the signals recorded on the antenna model under the radome, and the leaked charges for all considered lightning protection options are characteristic, first, for reverse discharges (types of impulse 1-3). The current impulses on the antenna of type 1 were characterized by the highest values of the current amplitude and the total transferred charge. For type 2 impulses, the current amplitude and the maximum total transferred charge were several times less than for type 1 current impulse.

At the same time, for the models of solid strip and segment lightning diverters, there is practically the same proportional relationship between the amplitude of the reverse current on the antenna and the amplitude of the discharge current pulse on the lightning diverter on the radome's outer surface (Figure 14). This is due to the fact that in the case of the formation of a discharge between the lightning diverter and ATC, when the negatively charged cloud is discharged, and/or in the case of the formation of a surface discharge on the radome shell's outer surface, when the negative charge accumulated on the outer shell surface is draining from the radome, the positive charge accumulated on the shell's inner surface becomes uncompensated. As a result, the electric field at the location of the antenna changes its direction to the opposite (a "reverse" field appears), and a powerful "reverse" discharge of the same polarity as the ATC itself is formed from the antenna under the radome. Moreover, the higher neutralization of negative charges in the ATC and on the radome's outer surface, the stronger the "reverse" field at the antenna location and the reverse discharge formed from it will be. It should be noted that for the same models of solid strip and segmented lightning diverters such an unambiguous relationship between the amplitude of the reverse current on the antenna and the steepness of the discharge current impulse on the lightning diverter on the outer surface has not been found (Figure 15). For strip and segmented lightning diverters, this dependence is different.

For current pulses of type 4 , which were induced on the antenna model by surface discharges in the radome and discharges between lightning diverters on its outer surface and ATC, a clearly expressed relationship between the amplitude of the induced signal and the setup of lightning protection of the radome model was not observed.

Thus, the possible mechanisms of the effect of lightning and thunderclouds on aircraft radomes and, accordingly, the parameters of the signals (current impulses) generated on the antenna under them as a result of such an effect, will depend on the accumulation of charges on the radome's inner and outer surfaces. This accumulation of charges occurs in the electric field created by a thundercloud. These fields can reach values of several $\mathrm{kV} / \mathrm{cm}[41,42]$. They are sufficient to initiate a corona discharge from the antenna structure under the radome. From this point of view, it may be important to use not only the spherical, but also flat antenna models in experimental studies $[8,25,26]$. The accumulation of charge on the radome's outer surface can also occur due to the processes of in-flight static electrification, especially under cloudy conditions and the presence of precipitation $[3,43]$. 


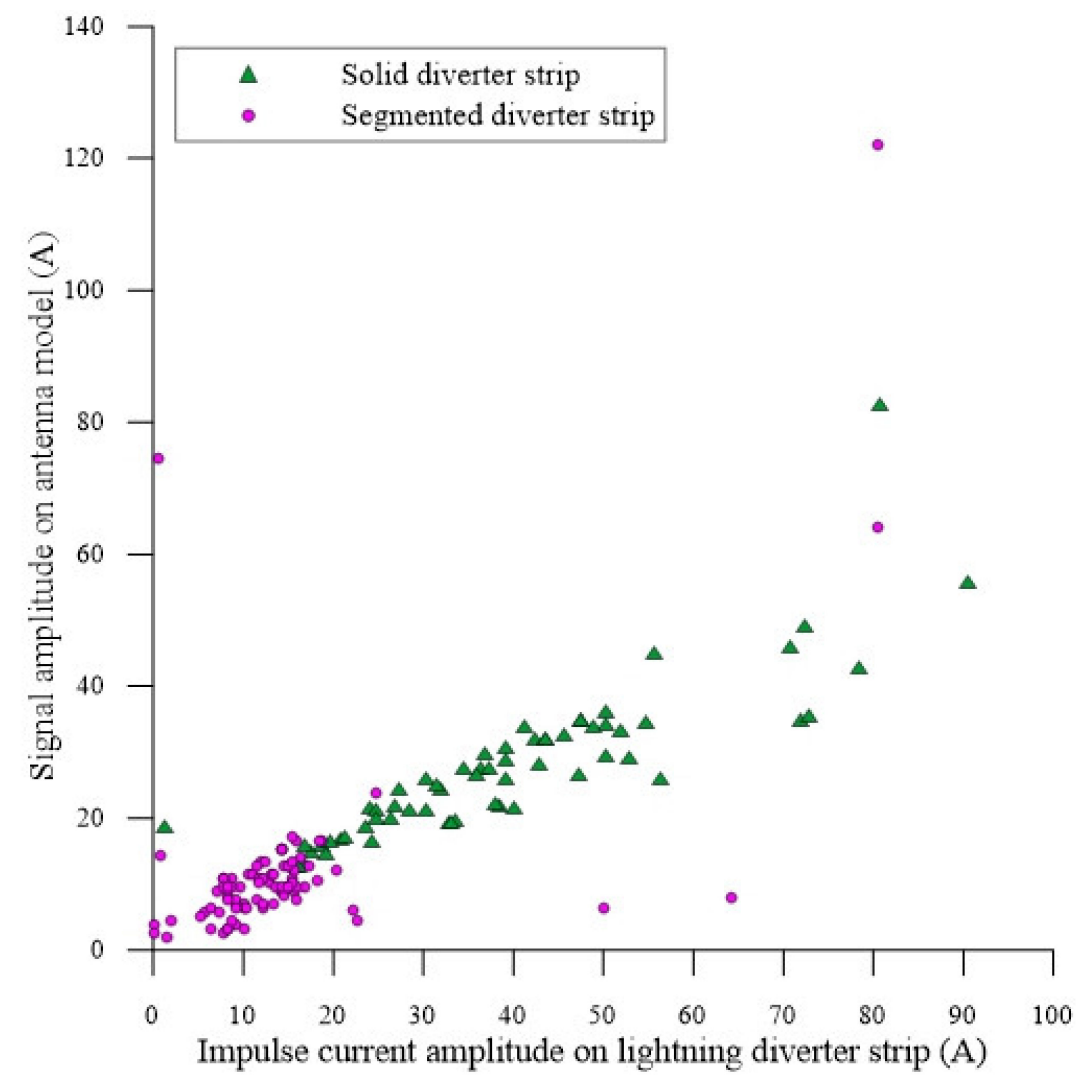

Figure 14. Dependence of the amplitude of the reverse current at the antenna on the amplitude of the current impulse at the lightning diverter (types of impulses 1-3).

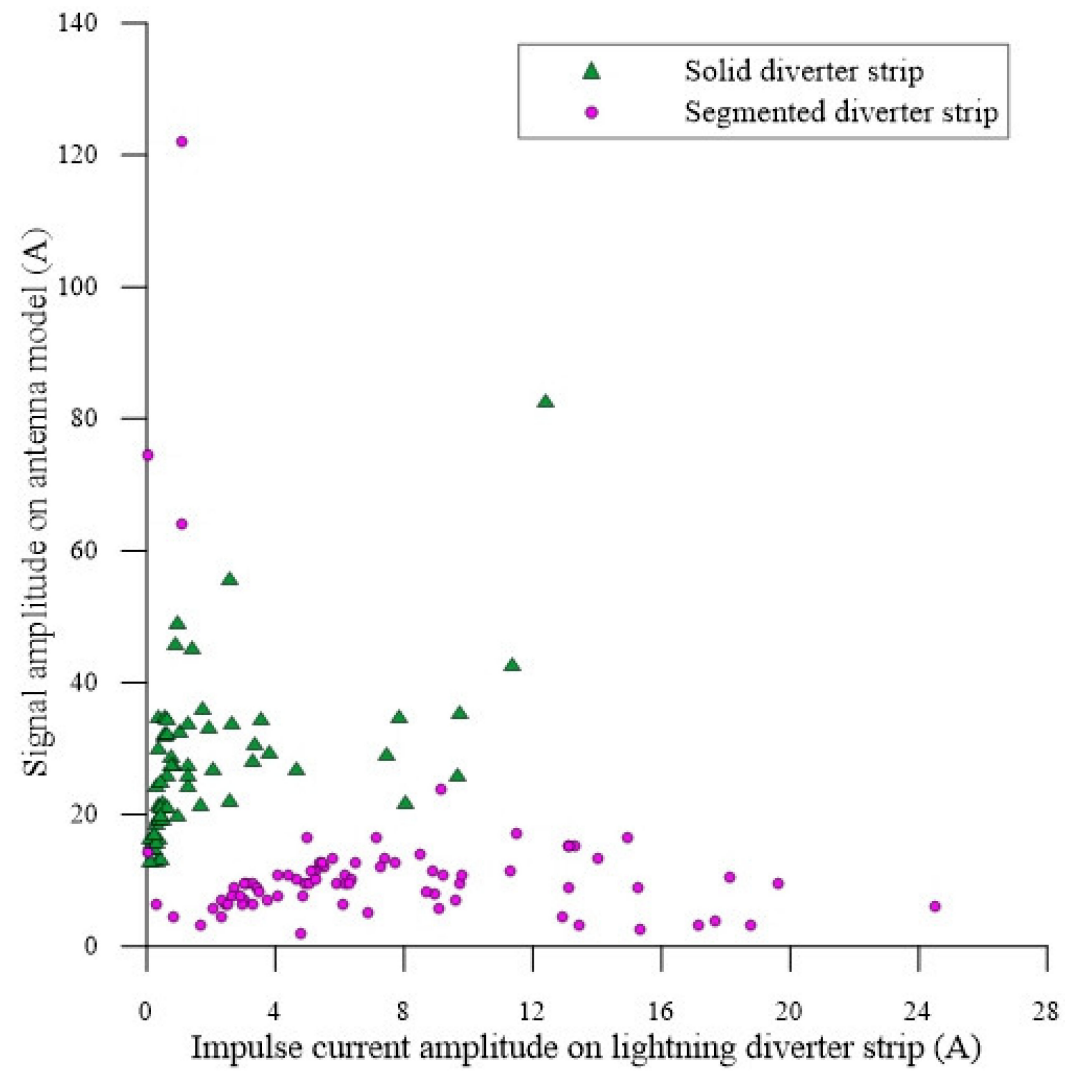

Figure 15. Dependence of the signal amplitude on the antenna on the steepness of the current impulse on the lightning diverter (types of impulses 1-3). 
The prevalence of one mechanism over another will be determined by the ratio of field intensities at the location of the antenna under the radome, inside radome's dielectric shell, and on its surface (especially in the locations of lightning diverters on the radome's surface). This field is created by charges deposited on the radome's inner and outer surfaces. After a significant charge has accumulated on the inner surface of the radome model, becoming largely compensated by the negative charge on radome's outer surface, generally the further development of events will depend on which is the weakest point in terms of discharge initiation in the gap (Figure 16).

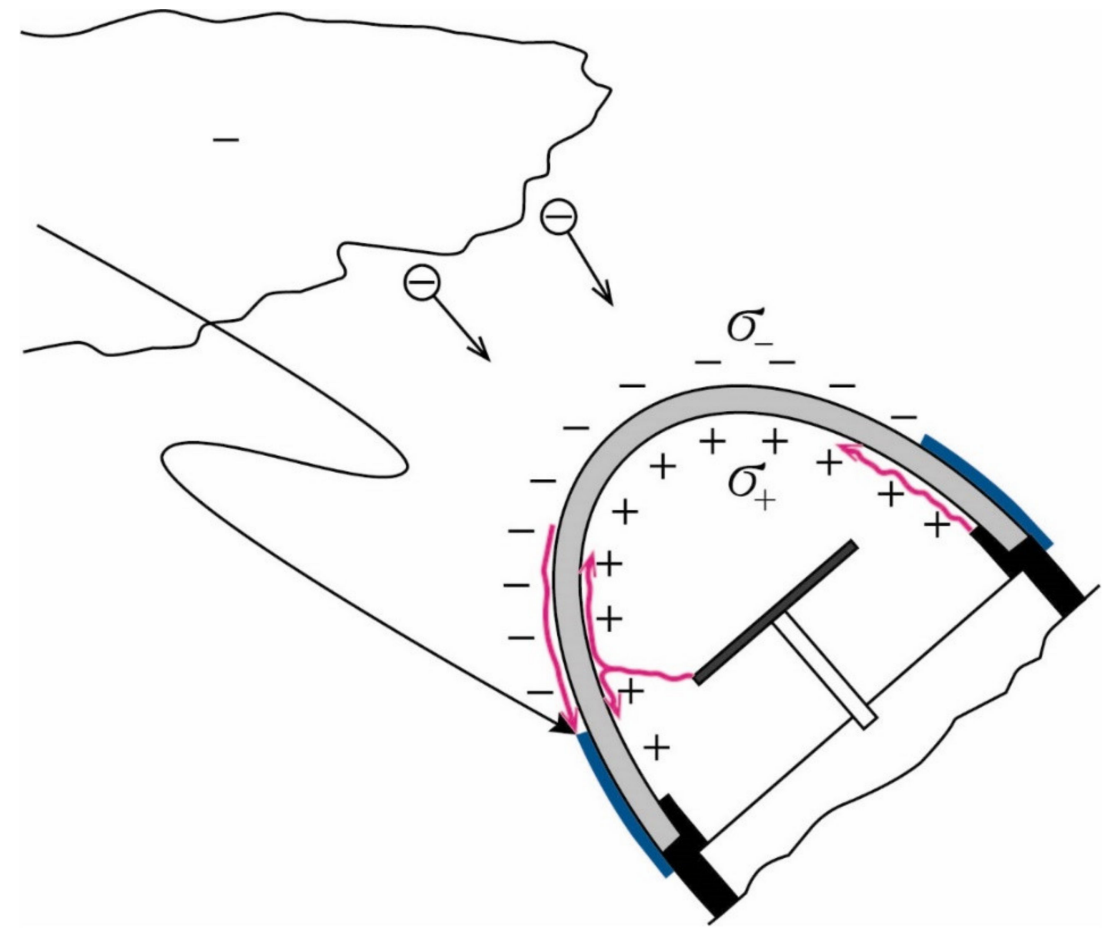

Figure 16. Formation of discharges from the antenna model and along the inner and outer radome surfaces in the presence of strip lightning diverters on the outer surface (not to scale).

When a corona discharge from the antenna occurs under the radome, then, in addition to the accumulation of a negative charge on the outer surface $\sigma-$, there will be an accumulation of a positive charge on its inner surface $\sigma+$, and this can create conditions for a breakdown of the radome shell. The possibility of such a development of events is determined by which of the mechanisms is activated earlier-either the surface discharges will begin along the radome's inner and or outer surface, or an electrical breakdown of the radome shell will occur. The very condition for the electrical breakdown of the shell will be presented as follows:

$$
\mathrm{E}_{\mathrm{env}}=\frac{\left|\sigma_{+}\right|}{2 \varepsilon \varepsilon_{0}}+\frac{\left|\sigma_{-}\right|}{2 \varepsilon \varepsilon_{0}} \geq \mathrm{E}_{\mathrm{br}}
$$

where $\mathrm{E}_{\mathrm{env}}$ is the electric field intensity in the radome shell; $\mathrm{E}_{\mathrm{br}}$ is the breakdown intensity of the shell material; $\varepsilon$ is the relative dielectric constant of the radome material. In (1), the effect of the external electric field of the ATC is not taken into account, since it is not decisive for the radome shell breakdown.

The processing of the experimental results showed that on average, the charge density on the radome's inner and outer surfaces can be in the range from several $\mu \mathrm{C} / \mathrm{m}^{2}$ to several hundred $\mu \mathrm{C} / \mathrm{m}^{2}$ (the highest values correspond mainly to the case of the absence of lightning diverters on the outer surface). It should be noted that the highest surface charge density will be observed in the region near the tip of the radome and in the areas opposite and above the edges of the antenna; therefore, the most probability of breakdown can be expected in these places. The surface area of these local areas does not exceed several 
hundred square centimeters. For an electrical breakdown of the shell in these places, it may be sufficient to accumulate a surface charge of the order of $5 \mu \mathrm{C}$. Thus, the probability of accumulation on the surface of the radome of a charge sufficient for the breakdown of its shell is quite real and is limited only by the electrical intensity along the surface of the shell.

If no breakdown of the radome shell occurs, then, in the general case, the field strength at the antenna under it is determined by three components: from the thunderstorm cell Eth, from the negative charge on the outer radome surface $\mathrm{E} \sigma-$, and from the positive charge on its inner surface E $\sigma+$.

$$
E_{\text {ant }}=\left|E_{\text {th }}\right|+\left|E_{\sigma-}\right|-\left|E_{\sigma+}\right|
$$

In (2) it is assumed that initially the total field from negative charges at the location of the antenna is greater than the field from positive charges. If one of the negative charges quickly disappears or decreases in magnitude, then the electric field will change significantly. This can happen when a discharge develops from a cloud or when it forms along the outer surface of the radome (Figure 16). In principle, both processes can take place practically simultaneously. Thus, one of the components in (2), either Eth, or E $\sigma-$ (or both), will significantly decrease.

The resulting electric field strength at the location of the antenna inside the radome changes direction to the opposite (a "reverse" field appears) and will be determined by a positive charge deposited on the inner radome surface, which in this case will become uncompensated.

$$
\mathrm{E}_{\mathrm{ant}} \sim \int_{\mathrm{S}} \frac{\sigma_{+} \mathrm{dS}}{4 \pi \varepsilon_{0} \mathrm{r}^{2}}
$$

where $\sigma_{+}$is the density of the positive charge on the inner surface; $S$ is the area of the radome surface where the positive charge is not compensated.

A powerful reverse discharge of the same polarity as the charge of the thunderstorm cell is formed from the antenna under the radome, which "collects" the charge accumulated on the inner surface through powerful surface discharges (Figure 16). As a result, a current impulse with a predominance of the reverse phase will act on the antenna under the radome.

The shape and amplitude of the current impulse on the antenna will depend on solid or segmented lightning diverter strips on the outer surface of the radome. The electric field at the location of lightning diverters is determined, in general, by three components-from a cloud, from a negative charge on the outer surface of the radome shell, and from a positive charge on the inner surface of the shell (Figure 16):

$$
\overrightarrow{\mathrm{E}}_{\text {str }}=\overrightarrow{\mathrm{E}}_{\mathrm{th}}+\overrightarrow{\mathrm{E}}_{\sigma-}+\overrightarrow{\mathrm{E}}_{\sigma+}
$$

In simulations, it is usually assumed that a thundercloud has the main negative charge at the bottom, and the plane approaches the thundercloud from below $[33,44]$. At the location of the lightning diverters, the total field of the negative charge of the cloud and the negative charge on the outer surface is greater than the field from the positive charge. As a result, it can be expected that first the conditions for the occurrence of a positive discharge from the top of the external lightning diverter are created. Moreover, it is easier to initiate and propagate a positive streamer and leader discharge, as the intensities required for the emergence of a positive leader are significantly less than for a negative discharge. The occurrence of a discharge between a thunderstorm cell and a lightning diverter on the radome's outer surface provokes the development of a discharge from the diverter along the outer surface of the radome (Figure 16). In principle, this surface discharge can be formed without a thundercloud discharge. The development of discharges along the outer surface sharply changes in magnitude and direction the electric field inside the radome. This applies both to the area at the top of the antenna and to the area near any electrodes on the inner surface of the lower portion of the radome. With the development of surface discharges, the "removal" of the blocking action of the cloud charge and the charge on 
the radome's outer surface occurs. This leads to a "reverse" discharge occurring from the antenna model under the radome (Figure 16).

The power of such a reverse discharge will depend on the amount of charge accumulated on the outer and inner surfaces, the degree of discharge of the nearest part of the cloud, and the intensity of the surface discharge.

In principle, with a sharp decrease in the action of the electric field of a negative charge on the outer surface and a negatively charged cell, the conditions for the formation of a "reverse" discharge can develop not inside the radome, not only at the location of the antenna, but also near the inner surface of its shell. A "reverse" discharge may start to form along the inner surface towards the base of the radome (fuselage) (Figure 16). As a result, a combined current impulse will be formed on the antenna under the radio-transparent radome due to the "reverse" discharge between the antenna and radome's inner surface, and due to the displacement currents induced on the antenna by both the leader current generated from the lightning diverter on the radome's outer surface, and by a powerful discharge current along the inner surface of the shell.

A specific picture of the formation of discharges on the radome's outer surface can be observed when segmented lightning diverters are used to protect it, when solid strip electrodes are replaced by metal segments placed with a certain pitch on the surface of the radome [8].

Metal segments on the radome surface of an aircraft flying near a thunderstorm cloud can serve as centers of accumulation of a charge formed on the surface due to static electrification during radome's interaction with various hydrometeors in the atmosphere, and charges deposited on radome's outer surface in the electric field of a thunderstorm cloud. In this case, the segmented electrodes, increasing the electric field in their vicinity, lead to a local accumulation of static electricity charges on them and on the dielectric surface in their immediate vicinity. The magnitude of these charges for each segment will be determined by several factors:

- The degree of static electrification of the dielectric surface near its vicinity;

- The size of an individual segment and the effect of the cloud's electric field and the field created by the charges accumulated on the radome's surface "far" from the segment under consideration;

- The appearance of a corona discharge from the antenna elements under the radome and, accordingly, the accumulation of charges of the opposite sign on the inner surface of the radome shell (including at the location of the segment on the outer surface);

- The location of successive segments relative to each other and the magnitude of the accumulated charges on these adjacent segments.

As a result, when the local electric field strength in the gap between the segments exceeds the critical value, the segments will play the role of a kind of multi-gap surge arrestor and through the surface discharges between the segments they can "start" discharges inside the radome and along its surfaces, forming a combined current impulse on the antenna under the radome.

\section{Conclusions}

Based on the investigations carried out using ATC, possible key mechanisms of the effect of thunderclouds and lightning discharges on radio-transparent aircraft radomes and equipment inside them have been determined, among which the following mechanisms are distinguished.

Accumulation of a charge on the radome's shell outer surface due to in-flight static electrification in cloudy conditions, and the deposition of air ions and charged aerosol particles on the surface of the radome under the action of a thundercloud's electric field, both lead to a significant increase of electric field intensity at the antenna's location under radome. As a result, a corona discharge is initiated from the antenna. The ions formed during this discharge (of the opposite sign than the charge of the thunderstorm cell) are deposited on the inner surface of the radome shell and accumulate there until the charge 
on the inner surface reaches such a value that it can reduce the field strength at the location of the antenna to a value below the inception strength.

As a result, charges of the opposite sign will accumulate on the outer and inner surfaces of the radome shell. Since the thickness of the shell is relatively small, the effect of these charges in the regions outside the shell itself and the air layers adjacent to it is practically compensated. Therefore, the process of accumulation of charges can last for a long time, and the local value of accumulated charges can reach tens to hundreds of $\mu \mathrm{C} / \mathrm{m}^{2}$. Such values of surface charges are quite achievable and the breakdown of the radome shell under their action is a rare but a probable event. As a result of such a breakdown, a powerful impulse of the induced current can form on the antenna, since the breakdown will be accompanied by the formation of rapidly developing high-current discharges along the outer and inner surfaces of the radome.

In the case of the formation of a surface discharge along the outer surface of the radome shell, when the charge accumulated there flows down onto the fuselage, the charge on the inner surface of the shell becomes uncompensated. A similar situation can arise when a discharge is formed from a solid or segmented lightning strip diverter towards a thundercloud, and a partial discharge of a thunderstorm cell. As a result, the electric field at the location of the antenna changes its direction to the opposite, and a powerful "reverse" discharge of the same polarity as the thunderstorm cell itself is formed from the antenna under the radome. The amplitude of the current impulse of such a discharge can be tens to hundreds of amperes, and even a few kA. In addition, such a "reverse" discharge can be accompanied by the formation of intense discharges towards the aircraft fuselage along the inner shell surface. The development of discharges from lightning strip diverters can also be accompanied by the formation of discharges along the outer shell surface. In addition to the "reverse" discharge current, significant displacement currents will be induced on the antenna. As a result, a combined current impulse with a predominance of the "reverse" phase or a combined current impulse of an arbitrary shape will be formed on the antenna under the radome, which will affect the equipment located inside it.

Maximal energy of electrostatic discharges depends on radome's size. Considering that accumulated charge (up to a few hundred $\mu \mathrm{C} / \mathrm{m}^{2}$ ) on the surface of model radome with the square space of several tens of $\mathrm{cm}^{2}$ provokes discharges from model antenna with current amplitude up to a few hundred amperes, it is possible to expect that as radome's size (and the square space of surface charges' accumulation) increases, impulse currents of discharges flowing through the antenna may reach up to several kA. Such impulse currents may have various spectral composition, and their effect on radio navigational equipment located under the radome may be dangerous, especially if their spectrums include frequencies similar the working frequencies of the radar and associated programming and computing equipment.

Author Contributions: Project administration, methodology A.T.; software, L.C. and O.B.; visualization, T.K.; investigation, A.O. and N.L.; writing—original draft preparation, V.V.; funding acquisition, D.K. and M.B. All authors have read and agreed to the published version of the manuscript.

Funding: This study conducted by Moscow Power Engineering Institute was financially supported by the Ministry of Science and Higher Education of the Russian Federation (project No. FSWF-20200019).

Institutional Review Board Statement: Not applicable.

Informed Consent Statement: Not applicable.

Data Availability Statement: Not applicable.

Conflicts of Interest: The authors declare no conflict of interest.

\section{References}

1. Larsson, C. The interaction between a lightning flash and an aircraft in flight. Comptes Rendus Phys. 2002, 3, 1423-1444. [CrossRef]

2. Uman, M.A.; Rakov, V.A. The interaction of lightning with airborne vehicles. Prog. Aerosp. Sci. 2003, 39, 61-81. [CrossRef] 
3. Hall, A. Thunderstorm Protection of Aircraft Radomes. In Proceedings of the International Conference on Lightning and Static Electricity, Seattle, WA, USA, 19-23 September 2005.

4. Petrov, N.; Haddad, A.; Griffiths, H.; Waters, R. Lightning strikes to aircraft radome: Electric field shielding simulation. In Proceedings of the 17th International Conference on Gas Discharges and their Applications, Cardiff, UK, 7-12 September 2008; pp. 513-516.

5. Petrov, N.I.; Haddad, A.; Petrova, G.N.; Griffiths, H.; Waters, R.T. Study of Effects of Lightning Strikes to an Aircraft, Recent Advances in Aircraft Technology; InTech: London, UK, 2012; pp. 523-544.

6. Karch, C.; Paul, C.; Heidler, F. Lightning Strike Protection of Radomes. In Proceedings of the International Symposium on Electromagnetic Compatibility EMC EUROPE, Barcelona, Spain, 2-6 September 2019. [CrossRef]

7. Karch, C.; Calomfirescu, M.; Rothenhäusler, M.; Brand, C.; Meister, H. FFS: Lightning Strike Protection of Radomes-An Overview. Conference: Deutscher Luft- und Raumfahrtkongress 2017, München 450139. Available online: https:/ / dlrk2017.dglr.de (accessed on 2 December 2021).

8. Karch, C.; Heidler, F.; Paul, C. Protection of Aircraft Radomes against Direct Lightning Strikes-An Overview. Atmosphere 2021, 12, 1141. [CrossRef]

9. Morgan, D.; Hardwick, C.J.; Haigh, S.J.; Meakins, A.J. The Interaction of Lightning with Aircraft and the Challenges of Lightning Testing; Aerospace Lab, Alain Appriou. 2012, pp. 1-9. Available online: https:/ / hal.archives-ouvertes.fr/hal-01184419/document (accessed on 2 December 2021).

10. Plumer, J.A.; Perala, R.A. Lightning Protection of Aircraft, 2nd ed.; Lightning Technologies Inc.: Pittsfield, MA, USA, 2014.

11. Uhlig, F.; Jones, C.; Vile, M.; Tagliana, B. Setup and statistical analysis of a database on in-flight lightning strike incidents. In Proceedings of the International Conference on Lightning and Static Electricity, Toulouse, France, 22-24 June 1999.

12. Jones, C.; Rowse, D.; Odam, G. Probabilities of catastrophe in lightning hazard assessments. In Proceedings of the International Conference on Lightning and Static Electricity, Seattle, WA, USA, 6-8 October 2001.

13. Lightning strike hazards on light aircraft. In Airworthiness Information Leaflet AIL/0014; Engineering360: Albany, NY, USA, 2001; Issue 2.

14. Lutz, M.; Casanova, R.; Revesz, T. Induced lightning testing of avionics-With single stroke, multiple stroke and multiple burst. In Proceedings of the 8th International Conference on Electromagnetic Interference and Compatibility, Chennai, India, 18-19 December 2003; pp. 333-338. [CrossRef]

15. Lago, F. Lightning in aeronautics. J. Phys. Conf. Ser. 2014, 550, 012001. [CrossRef]

16. Hoole, P.R.P.; Sharip, M.R.M.; Fisher, J.; Pirapaharan, K.; Othman, A.K.H.; Julai, N.; Rufus, S.A.; Sahrani, S.; Hoole, S.R.H. Lightning Protection of Aircraft, Power Systems and Houses Containing IT Network Electronics. J. Telecommun. Electron. Comput. Eng. 2017, 9, 1-7.

17. Petrov, N.; Petrova, G.; Haddad, A.; Griffiths, H.; Waters, R. Lightning strikes to aircraft radome: Simulation models and laboratory tests. In Proceedings of the International Conference on Lightning Protection, Uppsala, Sweden, $23-26$ June 2008.

18. Laroche, P.; Blanchet, P.; Delannoy, A.; Issac, F. Experimental Studies of Lightning Strikes to Aircraft; Issue 5-December, AL05-06; Aerospace Lab Journal: Chemin de la Hunière, France, 2012.

19. Vukovic, A.; Sewell, P.; Benson, T.M. Generating radome geometries for full lightning protection studies. In Proceedings of the 2019 ESA Workshop on Aerospace EMC, Budapest, Hungary, 1-5 May 2019; p. 8788907. [CrossRef]

20. Vukovic, A.; Sewell, P.; Benson, T. Impact of In Situ Radome Lightning Diverter Strips on Antenna Performance. IEEE Trans. Antennas Propag. 2020, 68, 7287-7296. [CrossRef]

21. Yan-Chao, D.; Xiu, X.; Ping-Dao, H. Research on aircraft radome lightning protection based on segmented diverter strips. In Proceedings of the 2017 International Symposium on Electromagnetic Compatibility-EMC EUROPE, Angers, France, 4-7 September 2017. [CrossRef]

22. Chen, H.; Wang, F.; Xiong, X. Plasma discharge characteristics of segmented diverter strips subject to lightning strike. Plasma Sci. Technol. 2019, 21, 025301. [CrossRef]

23. Vukovic, A.; Sewell, P.; Benson, T.M.; Jones, C.C.R.; Earl, S. Impact of Lightning Diverter Strips on Antenna Radiation Patterns. In Proceedings of the 14th European Conference on Antennas and Propagation (EuCAP), Copenhagen, Denmark, 15-20 March 2020. [CrossRef]

24. SAE. ARP (Aerospace Recommended Practice) 5412-Aircraft Lightning Environment and Related Test Waveforms; SAE Publications: Warrendale, PA, USA, 2000; Available online: https://www.sae.org/standards/content/arp5412/ (accessed on 2 December 2021).

25. Ulmann, A.; Brechet, P.; Bondiou-Clergerie, A.; Delannoy, A.; Lalande, P.; Blanchet, P.; Laroche, P.; Bocherens, E.; Bacchiega, G.L.; Gallimberti, I. New investigations of the mechanisms of lightning strike to radomes. Part I: Experimental study in high voltage laboratory. SAE Trans. J. Aerosp. 2001, 110, 325-331.

26. Delannoy, A.; Bondiou-Clergerie, A.; Lalande, P.; Blanchet, P.; Laroche, P.; Bacchiega, G.L.; Gallimberti, I. New investigations of the mechanisms of lightning strokes to radomes. Part II: Modeling of the protection efficiency. In Proceedings of the International Conference on Lightning and Static Electricity, Seattle, WA, USA, 6-8 October 2001; pp. 332-338. Available online: https://www.jstor.org/stable/44687238? refreqid=excelsior\%3Acfdeed90ff14bfd891708ad4320e2c77 (accessed on 1 December 2021). 
27. Plumer, A. System functional upset testing of aircraft electrical and avionics systems: How to approach the planning and conduct of the tests. In Proceedings of the International Conference on Lightning and Static Electricity, Seattle, WA, USA, 19-23 September 2005.

28. Hoole, P.R.P.; Fisher, J.; Pirapaharan, K.; Othman, A.K.H.; Julai, N.; Aravind, C.V.; Senthilkumar, K.S.; Hoole, S.R.H. De-termining Safe Electrical Zones for Placing Aircraft Navigation. Measurement and Microelectronic Systems in Static Thunderstorm Environment. Int. J. Control Theory Appl. 2017, 10, 16.

29. Smorgonskiy, A.; Rachidi, F.; Rubinstein, M.; Korovkin, N.V.; Vassilopoulos, A.P. Are Standardized Lightning Current Waveforms Suitable for Aircraft and Wind Turbine Blades Made of Composite Materials? IEEE Trans. Electromagn. Compat. 2017, 99, 1320-1328. [CrossRef]

30. SAE ARP 5416. Aircraft Lightning Test Methods; SAE International: New York, NY, USA, 2008.

31. Karch, C.; Lick, W.; Pack, S. Full-scale high voltage radome initial leader attachment tests. In Proceedings of the International Conference on Lightning and Static Electricity, Wichita, KS, USA, 10-13 September 2019.

32. EUROCAE ED-84. Aircraft Lightning Environment and Related Test Waveforms; European Organization for Civil Aviation Equipment: Paris, France, 2013.

33. Lalande, P.; Delannoy, A. Numerical Methods for Zoning Computation; Issue 5-December, AL05-08; Aerospace Lab Journal: Palaiseau, France, 2012.

34. Pavan, C.; Fontanes, P.; Urbani, M.; Nguyen, N.C.; Martinez-Sanchez, M.; Peraire, J.; Montanya, J.; Guerra-Garcia, C. Aircraft charging and its influence on triggered lightning. J. Geophys. Res. Atmos. 2020, 125, e2019JD031245. [CrossRef]

35. Antsupov, K.V.; Makalsky, L.M.; Sysoev, V.S.; Temnikov, A.G.; Vereshchagin, I.P. Upward leaders and discharges from a aerosol cloud. In Proceedings of the 9th International Conference on Atmospheric Electricity, St. Petersburg, Russia, 15-19 June 1992; pp. 360-363.

36. Vereshchagin, I.P.; Temnikov, A.G.; Orlov, A.V.; Stepanyanz, V.G. Computation of mean trajectories of charged aerosol particles in turbulent jets. J. Electrost. 1997, 40-41, 503-508. [CrossRef]

37. Temnikov, A.G.; Orlov, A.V.; Bolotov, V.N.; Tkach, Y.V. Studies of the parameters of a spark discharge between an artificial charged water-aerosol cloud and the ground. Tech. Phys. 2005, 50, 868-875. [CrossRef]

38. Temnikov, A.G. Using of artificial clouds of charged water aerosol for investigations of physics of lightning and lightning protection. In Proceedings of the IEEE Conference Publications: Lightning Protection (ICLP), Vienna, Austria, 2-7 September 2012. [CrossRef]

39. Temnikov, A.G.; Chernensky, L.L.; Orlov, A.V.; Lysov, N.Y.; Zhuravkova, D.S.; Belova, O.S.; Gerastenok, T.K. Application of Artificial Thunderstorm Cells for the Investigation of Lightning Initiation Problems Between a Thundercloud and the Ground. Therm. Eng. 2017, 64, 994-1006. [CrossRef]

40. Temnikov, A.G.; Chernensky, L.L.; Orlov, A.V.; Kivshar, T.K.; Lysov, N.Y.; Belova, O.S.; Zhuravkova, D.S. Peculiarities of the electric field calculation of the artificial thunderstorm cells. Int. J. Circuits Syst. Signal Process. 2018, 12, 305-311.

41. Rakov, V.A. Lightning Physics; COST P18; Training School on Lightning Physics and Effects: Kiten, Bulgaria, 2007 ; pp. 1-127.

42. Miller, K.; Gadian, A.; Saunders, C.; Latham, J.; Christian, H. Modelling and observations of thundercloud electrification and lightning. Atmos. Res. 2001, 58, 89-115. [CrossRef]

43. O'Neill, J.F. Static Electricity in Flight Threatens Aircraft Safety; Aviation mechanics bulletin, July/August; Flight Safety Foundation: Alexandria, VA, USA, 1992; pp. 1-21.

44. Fisher, J.; Hoole, P.R.; Pirapaharan, K.; Hoole, S.H. Pre-Lightning Strikes and Aircraft Electrostatics. MATEC Web Conf. 2017, 87, 05002. [CrossRef] 